\title{
Discovery and toxicological profiling of aminopyridines as orally bioavailable selective inhibitors of $\mathrm{Pl} 3$-kinase $\gamma$
}

Benjamin R Bellenie ${ }^{\dagger}$, Edward Hall, Ian Bruce ${ }^{\dagger}$, Matthew Spendiff ${ }^{\dagger}$, Andrew Culshaw ${ }^{\dagger}$, Sarah McDonald $^{\dagger}$, Ameet Ambarkhane ${ }^{\dagger}$, Colin Chinn ${ }^{\dagger}$, Matthew Thomas ${ }^{\dagger}$, Elisabeth Rosner $^{\dagger}$, Marguerite Bracher ${ }^{\dagger}$, Paul Nicklin ${ }^{\dagger}$, Stephen Marshall ${ }^{\dagger}$, Julie Coote ${ }^{\dagger}$, Eva Cullen ${ }^{\dagger}$, Clemence Tessier $^{\wedge}$; Kuno Wuersch^; Ajay Lal; Gillian Wallis`, Gregory J. Hollingworth ${ }^{\wedge}$, and James Neef*

Novartis Institutes for BioMedical Research, 250 Massachusetts Ave, Cambridge, MA 02139, Massachusetts, USA

${ }^{\wedge}$ Novartis Institutes for BioMedical Research, Novartis Campus, CH-4002 Basel, Switzerland

† Novartis Institutes for Biomedical Research, Horsham Research Centre, Wimblehurst Road, Horsham, West Sussex RH12 5AB, United Kingdom

*Corresponding author: james.neef@novartis.com

${ }^{*}$ Corresponding author: gregory.hollingworth@novartis.com

\section{Contents}

In Vitro Biology .52

Biochemical assays for $\mathrm{PI} 3 \mathrm{~K} \alpha, \beta$ isoforms

Biochemical assay for $\mathrm{PI} 3 \mathrm{~K} \gamma, \delta$ isoforms

Cellular assays for $\mathrm{PI} 3 \mathrm{~K} \alpha, \beta, \delta$ isoforms

Cellular assay for $\mathrm{PI} 3 \mathrm{~K} \gamma$ isoform

IL-8 Whole blood shape change assay

$\mathrm{PI} 3 \mathrm{~K} \alpha, \beta, \delta, \gamma$ isoform biochemical and cellular data for compounds 11-33

Kinase selectivity and safety panel assays for compound 33

KinomeScan ${ }^{\circledR}$ Treespot $^{\mathrm{TM}}$ interaction map for compound 33

ADME assays.

Microsomal clearance assay

High-throughput equilibrium solubility

Thermodynamic solubility (saturation shake flask method) 


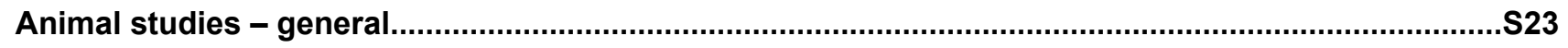

$\begin{array}{ll}\text { In vivo pharmacokinetic studies in rats } & \text { S23 }\end{array}$

$\begin{array}{ll}\text { Bioanalytical method for pharmacokinetics } & \text { S23 }\end{array}$

$\begin{array}{ll}\text { Solution vs suspension PK for } 16 & \text { S24 }\end{array}$

$\begin{array}{lr}\text { In vivo pharmacology studies } & \text { S24 }\end{array}$

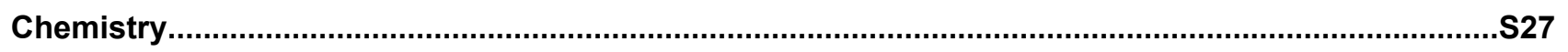

$\begin{array}{ll}\text { LCMS purity data for final compounds } & \text { S27 }\end{array}$

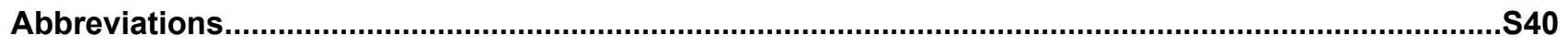

\section{$\underline{\text { In Vitro Biology }}$}

\section{Biochemical assays KinaseGlo format on PI3Ka and PI3K $\beta$}

The inhibitory kinase activities on PI3Ka and PI3K $\beta$ were determined using phosphatidyl inositol (PI) as substrate in n-Octyl-Glucoside (OG) using a luminescence assays based on ATP consumption (KinaseGlo). Some $50 \mathrm{nl}$ of compound dilutions were dispensed onto black 384-well plates (Greiner Cat. No.784076). L-a-

phosphatidylinositol $(\mathrm{PI})$, provided as $10 \mathrm{mg} / \mathrm{ml}$ solution in methanol, was transferred into a glass tube and dried under nitrogen beam. It was then resuspended in $3 \%(v / v)$ Octylglucoside by vortexing and stored at $4^{\circ} \mathrm{C}$. Some $4.5 \mu \mathrm{l}$ of a mix of PI/OG with $10 \mathrm{nM} \mathrm{PI3Ka}$ or $0.75 \mu \mathrm{g} / \mathrm{ml} \mathrm{PI3K} \beta$ was added. The kinase reactions were started by addition of $4.5 \mu \mathrm{l}$ of ATP-mix containing in a final volume of $9 \mu \mathrm{l}$ the following: $10 \mathrm{mM}$ TRIS-HCl pH 7.5, $3 \mathrm{mM}$ $\mathrm{MgCl} 2$ or $3 \mathrm{mM} \mathrm{MnCl} 2,50 \mathrm{mM} \mathrm{NaCl}, 0.05 \%$ CHAPS, $1 \mathrm{~m}$ MAKT DTT and $1 \mu \mathrm{M} \mathrm{ATP}$. The reactions were carried out at room temperature (RT) for either 30 or 60 minutes (PI3Ka or PI3Kß, respectively) stopped with $9 \mu$ of Kinase Glo and plates were read 10 minutes later in a Synergy 2 reader using an integration time of 0.1 seconds per well. To generate the $100 \%$ inhibition of the kinase reaction PI/OG in kinase buffer without addition of recombinant kinases was used while the $0 \%$ inhibition was given by the solvent vehicle ( $90 \% \mathrm{v} / \mathrm{v}) \mathrm{DMSO})$ in water in the presence of recombinant kinases.

\section{ADAPTA format on PI3Ky and PI3Kס}

The kinase assay format used for measuring the activity on $\mathrm{PI} 3 \mathrm{KY}$ and $\mathrm{PI} 3 \mathrm{~K} \delta$ is non-radioactive and monitors the formation of ADP TR-FRET (ADAPTA). Some $50 \mathrm{nl}$ of compound dilutions were dispensed onto white 384-well small volume polystyrene plates. Then, $4.5 \mu \mathrm{l}$ of PI3K substrate PI followed by $4.5 \mu$ l of ATP (final assay volume 9 
$\mu \mathrm{L}$ ) are incubated at RT. The standard reaction buffer for the Adapta ${ }^{\mathrm{TM}}$ TR-FRET assay contained $10 \mathrm{mM}$ Tris$\mathrm{HCl} \mathrm{pH} \mathrm{7.5,} 3 \mathrm{mM} \mathrm{MgCl}$, $50 \mathrm{mM} \mathrm{NaCl}, 1 \mathrm{mM} \mathrm{DTT}$, and 0.05\% (v/v) CHAPS. Reactions were stopped with $4.5 \mu \mathrm{l}$ of a mixture of EDTA containing the Eu-labeled anti-ADP antibody and the Alexa Fluor $® 647$ - labeled ADP tracer in TR-FRET dilution buffer. Plates are read 30 to 60 minutes (PI3KY or PI3Kס, respectively) later in a Synergy2 reader using an integration time of 0.4 seconds and a delay of 0.05 seconds. Control for the $100 \%$ inhibition of the kinase reaction was performed by replacing the PI3K by the standard reaction buffer. The control for the $0 \%$ inhibition was given by the solvent vehicle of the compounds (90\% DMSO in $\mathrm{H} 2 \mathrm{O}$ ). IC50 values obtained via KinaseGlo and ADAPTA values have been shown to be equivalent/comparable.

\section{Cellular assays for PI3K $\alpha, \beta$ or $\delta$ isoforms}

Rat-1 fibroblast cells stably overexpressing a myristoylated form of the catalytic subunit of human PI3Ka, $\beta$ or $\delta$ were plated in 384-well plates at a density of 7500,6200 , or 4000 cells (PI3Ka, $\beta$ and $\delta$, respectively) in $30 \mu \mathrm{l}$ complete growth medium (Dulbecco's modified Eagle's medium (DMEM high glucose) supplemented with $10 \%$ ( $\mathrm{v} / \mathrm{v}$ ) fetal bovine serum, $1 \%$ (v/v) MEM non-essential amino acids, $10 \mathrm{mM} \mathrm{HEPES,} 2 \mathrm{mM}$ L-glutamine, $10 \mu \mathrm{g} / \mathrm{ml}$ puromycin and 1\% (v/v) Penicillin/Streptomycin) and were incubated at 37\% / 5\%CO2 / 95\% humidity for 24 hours. Compounds were diluted in 384-well plates to obtain 8-point serial dilutions in 90\% DMSO, as well as 4 reference compounds plus 16 high controls and 16 low (inhibited) controls. Pre-dilution plates were prepared by dispensing pipetting $250 \mathrm{nl}$ of compound solutions into 384-well polypropylen plates using a Hummingwell nanoliter dispensor. Compounds were pre-diluted by the addition of $49.75 \mu \mathrm{l}$ complete growth medium. $10 \mu \mathrm{l}$ of pre-diluted compound solution were transferred to the cell plate using a 384-well pipettor, resulting in a final DMSO concentration of $0.11 \%$. Cells were incubated for $1 \mathrm{~h}$ at $37 \% \mathrm{C} / 5 \% \mathrm{CO} 2 / 95 \%$ humidity. The supernatant was removed, the cells were lysed in $20 \mu$ of lysis buffer for AlphaScreen $®$ SureFire $®$ detection. For detection of p-AKT(Ser473), the SureFire ${ }^{8}$ p-Akt 1/2 (Ser473) Assay Kit (PerkinElmer, U.S.A) was used. Some $5 \mu$ l of cell lysate was transferred to 384-well low volume Proxiplates for detection using a 384-well pipettor. Addition of AlphaScreen $\circledast$ SureFire $®$ reagents was done according to the manufacturer'sprotocol. First, $5 \mu$ l of reaction buffer plus activation buffer mix containing AlphaScreen ${ }^{\circledR}$ acceptor beads was added, the plate was sealed, and incubated on a plate shaker for 2 hours at RT. Second, $2 \mu$ of dilution buffer containing AlphaScreen $®$ donor beads was added, and the plate was incubated on plate shaker as above for a further 2 hours. The plate was read on an AlphaScreen $®$ compatible plate reader, using standard AlphaScreen $®$ settings. Measurement of activity on PI3KY in MIP-1a-stimulated U937 monocytes. U937 cells were starved seeding them in HBSS (Life Technologies \#14025-050) at a concentration of 2x105 cells/well into a 384-well plate and incubated in a humidified incubator $\left(37^{\circ} \mathrm{C}, 5 \% \mathrm{CO} 2\right)$ for 1.5 hours. Cells were incubated with serial dilutions of compounds in a final volume of $100 \mu \mathrm{l}$ per well for 30 minutes $\left(37^{\circ} \mathrm{C}\right)$. PI3Ky-activity was stimulated by addition of $10 \mathrm{ng} / \mathrm{ml} \mathrm{MIP}-1$ alpha (R\&D Systems \#270-LD) for 3 minutes $\left(37^{\circ} \mathrm{C}\right)$. Stimulation was stopped by incubating the cell plates on ice for 10 minutes. Cells were centrifuged at $1200 \mathrm{rpm}, 4^{\circ} \mathrm{C}$ for 5 minutes. Supernatant was removed and cells were lysed by addition of $30 \mu$ ice cold lysis buffer from the HTRF Phospho-AKT (Ser473) assay kit (cisbio \#64AKSPEH) and incubated on ice for $15 \mathrm{~min}$. Some $16 \mu \mathrm{l}$ lysates were transferred to a 384- well ProxiPlate Plus (Perkin Elmer \#6008239). Two $\mu$ l of each antibody-conjugate diluted 1:20 with detection reagent were added to each well and the plate was kept in the dark at RT for 4 hours. Fluorescence was measured at excitation of 620 
$\mathrm{nm}$, emission at $665 \mathrm{~nm}$ with a Pherastar Reader (BMG Labtech). Measurement of activity on PI3Ky in mouse bone marrow-derived mast cells (BMMCs). Bone marrow cells were collected from femurs of C57/BI6 mice, resuspended in Iscove's Modified Dulbecco's Medium supplemented with 1\% FCS, 2 mM L-glutamine, Pen/Strep (1:100), $50 \mu \mathrm{M}$ beta-MSH, $4 \mathrm{ng} / \mathrm{ml}$ murine IL-3 (m-IL-3) and incubated at $37^{\circ} \mathrm{C}, 5 \% \mathrm{CO}$. After 3 days nonadherent cells were re-cultivated in a mixture of $20 \%$ old and $80 \%$ fresh growth medium. m-IL3 was supplied every 2-3 days and suspension cells were passaged once a week allowing differentiation and accumulation of BMMCs which were identified by FACS as a cell population expressing both, C-KIT (SCF-receptor) and FcEreceptor (double stain with PE-conjugated hamster anti-mouse FceR from e BioScience \# 12-5898-83 and APCconjugated rat-anti-mouse CD117/ckit from BioLegend \#105812). After several (4-6) weeks, the cultures contained more than $90 \%$ mast cells. The BMMCs could be kept in culture for up to10 weeks. Assays were performed in 384 well plates using 105 BMMCs per well suspended in DMEM, 0.1 \% BSA. Cells were incubated with serial dilutions of compounds in a final volume/well of $100 \mu \mathrm{l}$ for 1 hour $\left(37^{\circ} \mathrm{C}\right)$ followed by removal of $80 \mu \mathrm{l}$ culture supernatant. PI3Ky-activity was stimulated by addition of $4 \mu \mathrm{l}$ adenosine (final: $2 \mu \mathrm{M})$ for 3 minutes $\left(37^{\circ} \mathrm{C}\right)$. Stimulated cells were lysed by addition of $6 \mu \mathrm{l}$ X cold lysis buffer from the p AKT(Ser473) Sure-Fire Kit (Perkin Elmer) and incubation for $15 \mathrm{~min}$ on ice yielding $30 \mu \mathrm{l}$ cell lysate per well. Some $5 \mu$ l of the supernatants were used to determine AKT phosphorylation with the SureFire Kit (according to the instructions of the supplier).

\section{Cellular U937 AKT assay for PI 3-kinase gamma}

The U937 monocyte cell line is maintained in a basal medium of RPMI 1640 supplemented with $10 \%$ heat inactivated FBS, 100U/ml Penicillin, 100ug/ml streptomycin and 2mM L-glutamine (Invitrogen). U937 suspension culture is maintained by seeding cells at a density of $0.125 \times 10^{6}$ cells per $\mathrm{ml}$ in fresh medium every three or four days. Cells are incubated at $37^{\circ} \mathrm{C}, 5 \% \mathrm{CO} 2$. Three or four days prior to assay, cells are seeded at a density of $0.25 \times 10^{6}$ cells per $\mathrm{ml}$ in a total volume of $40 \mathrm{ml}$ in a T162 culture flask.

Before beginning the cell manipulations described below, the MSD (Meso Scale Discovery) assay plate is blocked by addition of $150 \mu \mathrm{l} /$ well blocking buffer supplied and incubated with shaking for a minimum of one hour at room temperature. All steps of the assay must be performed quickly, with accurately timed incubation periods and observing temperature controls where indicated. Cells seeded at $0.25 \times 106 / \mathrm{ml} 3$ or 4 days prior to the assay are aspirated, transferred to a $50 \mathrm{ml}$ falcon tube, counted and centrifuged for eight minutes at $300 \mathrm{~g}$ at room temperature. Supernatant is aspirated, the cell pellet resuspended and washed once in HBSS (Hank's Balanced Salt Solution) by centrifugation for eight minutes at $300 \mathrm{~g}$ at room temperature. The cell pellet is resuspended in HBSS to a concentration of $4 \times 10^{6}$ per $\mathrm{ml}$, and $100 \mu \mathrm{L}$ of cell suspension added to each well of a flat-bottomed 96well tissue culture plate. Assay plates are incubated for 1.5 hours at $37^{\circ} \mathrm{C}, 5 \% \mathrm{CO}_{2}$ to allow background AKT phosphorylation to reduce before the compound stimulation step. A $5 \mathrm{mM}$ stock concentration of compound is prepared in $100 \%$ DMSO; from this a 1 in 125 dilution is made in HBSS giving a top compound concentration of $40 \mu \mathrm{M}, 0.8 \%$ DMSO.

Compound titrations are prepared in a fresh flat-bottomed, 96 -well plate, by 10 -fold serial dilution of $40 \mu \mathrm{M}$ into HBSS $0.8 \%$ DMSO; pipette tips are replaced after each dilution is made. Compound concentrations at this stage are 4-times the final concentration required in the assay plate. Cells are stimulated with compound or HBSS $0.8 \%$ 
DMSO by direct transfer of $50 \mu \mathrm{l} /$ well from the compound dilution plate. The assay plate containing compoundtreated cells is then incubated for 30 minutes at $37^{\circ} \mathrm{C}$. A standard plate layout is used for allexperiments. Compound-treated cells, in addition to positive control wells ("max MIP1a"), are stimulated with 50 $\mu$ L per well of 40ng/ml MIP1a (R\&D Systems catalogue number 270-LD, lyophilized stock reconstituted to $50 \mu \mathrm{g} / \mathrm{ml}$ with PBS $0.1 \%$ BSA). Negative control wells ("min HBSS"), are stimulated with $50 \mu \mathrm{l} /$ well of HBSS in the absence of MIP1 $\alpha$.

Final compound concentrations are now diluted 4-fold giving a top concentration of $10 \mu \mathrm{M}$; where added, the final concentration of MIP1 $\alpha$ is $10 \mathrm{ng} / \mathrm{ml}$. Cells are incubated with MIP1 $\alpha$ for 3 minutes, at $37^{\circ} \mathrm{C}, 5 \% \mathrm{CO}$. After the three minute stimulation period, the assay plate is kept ice cold at all times. Assay plates are centrifuged for 2 minutes at $300 \mathrm{~g}, 4^{\circ} \mathrm{C}$ and supernatant is removed by gently inverting, and then blotting the plate on tissue. Cells are then washed by gentle addition of $150 \mu \mathrm{L} /$ well of ice cold HBSS and centrifugation at $300 \mathrm{~g}$, for 5 minutes at $4^{\circ} \mathrm{C}$. Supernatant is aspirated and the plate blotted as described above. The plate is placed on ice and cells are immediately treated with $35 \mu \mathrm{L}$ per well of ice cold lysis buffer, prepared according to the kit instructions (per assay plate, to $5 \mathrm{ml}$ of Tris lysis buffer add $100 \mu \mathrm{l}$ of $50 \mathrm{x}$ protease inhibitor solution and $50 \mu \mathrm{l}$ of each $100 \mathrm{x}$ phosphatase inhibitor solutions I and II). Plates are incubated on ice for 20 minutes before centrifugation at $841 \mathrm{~g}$ for 5 minutes, $4^{\circ} \mathrm{C}$. Block buffer is aspirated from the MSD plate, and the plate washed four times with $300 \mu / /$ well Tris wash buffer. $25 \mu \mathrm{L}$ of cell lysate is then transferred from the assay plate to the washed MSD plate which is sealed and incubated at room temperature for one hour with shaking. The plate is washed four times with $300 \mu \mathrm{L}$ per well of Tris wash buffer before addition of $25 \mu \mathrm{L}$ per well of sulfo-tag anti-total AKT/pAKT detection antibody $(60 \mu \mathrm{l}$ of $50 \mathrm{x}$ antibody stock is diluted in $1 \mathrm{ml}$ block buffer mixed with $2 \mathrm{ml}$ wash buffer) and incubated at room temperature for one hour with shaking. The plate is washed four times with $300 \mu l$ per well of Tris wash buffer and $150 \mu \mathrm{l}$ per well of Read buffer is added, taking care to avoid the introduction of bubbles. The plate is immediately read using an MSD SECTOR Imager 6000. Results are exported in Excel and the percentage of phosphorylated AKT is calculated using the equation: \% Phosphoprotein $=\left(\left(2^{*}\right.\right.$ Phospho signal $) /($ Phospho signal + Total signal) $)^{*}$ 100. Compound-mediated inhibition of AKT phosphorylation is analysed using Prizm V Graphpad software.

\section{High Throughput Cellular U937 AKT assay for PI 3-kinase gamma}

Materials used: Bio-Rad TC10TM automated cell counter, Bio-RAD counting slides (\#145-0011), Trypan blue solution 0.4\% (\#T8154 Sigma), diluted 1:2 in PBS), Bioconcept Multidrop combi, Versette automated liquid handler (Thermo scientific), HTRF Phospho-AKT (Ser473) 10'000 tests assay kit (cisbio\#64AKSPEH), ProxiPlate384 Plus, White, TC treated (Perkin Elmer \#6008239) 384-well tissue culture treated plate (BD Falcon \#353289), RPMI + GlutaMAX (Life Technologies \#61870-010), FBS dialyzed (Life Technologies \#26400), Penicilin/Streptomycin (Life Technologies \#15140), HBSS 1X (Life Technologies \#14025-050), Wortmannin (Sigma-Aldrich \# W1628), stock solution 10mM in 90\% DMSO, Recombinant Human CCL3/ MIP1a (R\&D Systems \#270-LD) (stock solution 10 $\mathrm{g} / \mathrm{ml}$ ), RUBYstar Microplate Reader (BMG Labtech \#8) U937 cells are split every 3-4 days: $5 \times 10^{6}$ cells/ flask $\left(175 \mathrm{~cm}^{2}\right)$ in $40 \mathrm{ml}$. $3-4$ days before the assay, cells should be seeded: $4-5$ flasks with 107 cells in $40 \mathrm{ml}$. Semi-automated preparation of cell lysates: Cells were resuspended in HBSS, seeded (200'000cells/well/60 $\mathrm{\mu l}$ ) into a 384 -well plate and incubated in a humidified $37^{\circ} \mathrm{C}, 5 \% \mathrm{CO} 2$ incubator for

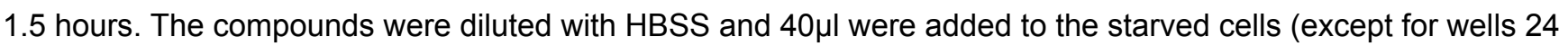


$\mathrm{I}-\mathrm{P}$ ). $10 \mu \mathrm{M}$ Wortmanin was added to the negative control (wells $24 \mathrm{I}-\mathrm{P}$ ). The cells were then incubated for 30 minutes at $37^{\circ} \mathrm{C}$ and $5 \% \mathrm{CO} 2$. Stimulation occurred during 3 minutes by addition of $20 \mu \mathrm{MIP} 1 \alpha$ (final $10 \mathrm{ng} / \mathrm{ml}$, diluted in HBSS) in the incubator. Wells $24 \mathrm{~A}-\mathrm{H}$ were only stimulated with HBSS. The stimulation was then stopped by putting the cell plates on ice (filled with cold water). The cells were then centrifuged at 1200rpm and $4^{\circ} \mathrm{C}$ for 3 minutes. $80 \mu \mathrm{l}$ of supernatant was removed. The cells were again centrifuged at $1200 \mathrm{rpm}$ and $4^{\circ} \mathrm{C}$ for 3 minutes. The supernatant was then removed by turning plates upside down and $30 \mu$ of lysis buffer were added. The plate was incubated at room temperature for 30 minutes under shaking. $16 \mu l$ were then transferred to a ProxiPlate Plus 384-well. $4 \mu \mathrm{l}$ of the master mix (each conjugate diluted 1:20 with detection reagent) were added to each well and the plate was kept in the dark at room temperature for 4 hours. Fluorescence was measured at $665 \mathrm{~nm}$ and $620 \mathrm{~nm}$ with RUBYstar Reader.

\section{Whole blood neutrophil shape change assay}

A flow cytometry based method used to measure the inhibition of IL-8 (interleukin-8)-induced neutrophil shape change in human whole blood.

\section{$\underline{\text { Reagents, Material \& Equipment }}$}

Sterile Distilled Water, Baxter \# UKF117

10X CellFIX solution, BECTON DICKINSON Biosciences \# 340181

IL-8, R\&D Systems \# 208-IL

DMSO, Hybri-Max, Sigma-Aldrich \# D2650

Dulbecco's Phosphate Buffered Saline 1X [ $\left.{ }^{+}\right] \mathrm{CaCL}_{2}, \mathrm{MgCL}_{2}$, gibco by life technolgies \#14040

Albumin Solution from Bovine Serum (30\%), Sigma Aldrich \# A9576-50ml

Ammonium Chloride $\mathrm{NH}_{4} \mathrm{CL}$, Sigma Aldrich \# A0171

Potassium Bicarbonate $\mathrm{KHCO}_{3}$, Sigma Aldrich \# P9144

K2 EDTA Vacutainers, Becton Dickinson Vacutainer ${ }^{\circledR} \# 367525$

96-well Polypropylene deep-well plates, VWR \# PORV219009

96 well Plates, V-bottom with lid, Costar \# 3894

96 well Polypropylene Plates, Round Bottom, Greiner \# 650261 (for HIGH THROUGHPUT SAMPLER FACS)

120 $\mu$ l pre-sterilized Biohit Filter Tips, Biohit \#790101F

350 $\mu$ l pre-sterilized Biohit Tips, Biohit \#790350

1200ul pre-sterilized Biohit Tips, Biohit \# 791202

Biohit e1200 Electronic 8-channel Pipette 
Biohit e120 Electronic 8-channel Pipette

Eppendorf Research Plus 100-1000 $\mu$ Pipette

Eppendorf Research Plus 20-200 $\mu$ I Pipette

Becton Dickinson Biosciences FACS Canto II Flow Cytometer with high throughput sampler.

IL-8 was made up to $2 \mu \mathrm{M}$ stocks in $0.1 \%$ bovine serum albumin/PBS and stored at $-80^{\circ} \mathrm{C}$. On the day IL-8 was diluted in PBS (phosphate buffered saline) 10 minutes before use. IL-8 was used at final concentration of 2nM and a concentration range from 0.003 to $200 \mathrm{nM}$ for the donor dose response curve. _Assay fixative solution was prepared fresh each day from 10X concentrated CellFIX ${ }^{\mathrm{TM}}$ solution diluted 1:10 in sterile distilled water and then 1:4 with PBS. Assay fixative solution was kept on ice prior to use._A 10X lysis buffer was prepared in advance by dissolving $20.75 \mathrm{~g} \mathrm{NH}_{4} \mathrm{Cl}$ and $2.5 \mathrm{~g} \mathrm{KHCO}_{3}$ in $250 \mathrm{ml}$ sterile $\mathrm{H}_{2} \mathrm{O}$. This $10 \mathrm{X}$ lysis buffer was filtered under sterile conditions and stored for up to two weeks at $4^{\circ} \mathrm{C}$. On the day a $1 \mathrm{X}$ lysis solution was prepared with sterile distilled $\mathrm{H}_{2} \mathrm{O}$ and kept on ice prior to use. The test compounds were prepared as $10 \mathrm{mM}$ stock solutions in $100 \%$ DMSO and were stored at $4^{\circ} \mathrm{C}$. Once in use for an assay $10 \mathrm{mM}$ stock compounds were thawed and stored at RT protected from light. Compound dilutions were prepared fresh on the day. The first series of dilutions in $100 \%$ DMSO were done first thing in the morning. Only once blood had been collected and arrived in laboratory was the next set of dilutions into PBS carried out (1:10 PBS, 10\% DMSO). This limited the exposure of diluted compound to plastic and made sure the exposure timing was consistent between assays. Compounds were added to the deep 96 well plates at 10X the final desired concentration (with addition of blood final [DMSO] $=1 \%$ ).

Table S-1

\begin{tabular}{|c|c|c|c|}
\hline $\begin{array}{c}\mathbf{1 0 0} \% \text { DMSO } \\
\text { Serial Dil'n } \mathbf{1} \text { in } \mathbf{4}\end{array}$ & $\begin{array}{c}\mathbf{1 0 \%} \mathbf{D M S O} \\
\mathbf{1} \text { in } \mathbf{1 0} \mathbf{~ P B S}\end{array}$ & $\begin{array}{c}\mathbf{1} \% \mathbf{D M S O} \\
\text { Assay Plate }\end{array}$ & example Well ID* \\
\hline $10000 \mu \mathrm{M}$ & $1000 \mu \mathrm{M}$ & $100 \mu \mathrm{M}$ & $B 2 ; C P D+I L-8$ \\
\hline 2500 & 250 & 25 & $B 3 ; C P D+I L-8$ \\
\hline 625 & 62.5 & 6.25 & $B 4 ; C P D+I L-8$ \\
\hline 156.25 & 15.62 & 1.56 & $B 5 ; C P D+I L-8$ \\
\hline 39.0625 & 3.9 & 0.39 & $B 6 ; C P D+I L-8$ \\
\hline 9.765625 & 0.97 & 0.097 & $B 7 ; C P D+I L-8$ \\
\hline 2.441406 & 0.24 & 0.024 & $B 8 ; C P D+I L-8$ \\
\hline 0.610352 & 0.06 & 0.006 & $B 9 ; C P D+I L-8$ \\
\hline $100 \%$ DMSO & $10 \%$ DMSO & $1 \%$ DMSO & $B 10 ;+I L-8$ \\
\hline $100 \%$ DMSO & $10 \%$ DMSO & $1 \%$ DMSO & $B 11 ;+P B S$ \\
\hline
\end{tabular}

Table S-1 illustrates the compound dilution series used in human whole blood neutrophil shape change assay.

On the day of running the assay, assay fixative buffer and $1 \mathrm{X}$ lysis solutions were prepared and stored on ice. Compound dilutions in $100 \%$ DMSO were prepared as described previously. Human whole blood was collected in 
K2 EDTA Vacutainers. Once blood was in the laboratory, compound dilutions into PBS were carried out as described previously and depicted in Table 1. 10 $\mu$ of 10X final compound concentration was added to appropriate wells of a deep 96-well plate except controls where $10 \mu \mathrm{l}$ of $10 \%$ DMSO was added in place of compound, as outlined in the dilution series in Table1. The outer wells of the deep well assay plate were filled with 1200 $\mu$ l of sterile distilled $\mathrm{H}_{2} \mathrm{O}$ in an effort to limit edge effects (rows $\mathrm{A} 1-\mathrm{H} 1, \mathrm{~A} 1-\mathrm{A} 12, \mathrm{~A} 12-\mathrm{H} 12$ ). An IL-8 dose response was determined for each blood donor examined, to monitor the donor response to IL-8. At this step in assay preparation for the IL-8 dose response samples $10 \mu$ l of PBS was added to designated wells. In addition the assay window

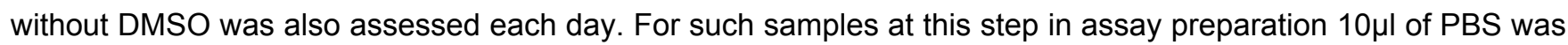
added in the place of $10 \%$ DMSO. $80 \mu$ l of whole blood was added to compound/10\% DMSO/PBS and mixed once gently upon addition. Lids were placed on the 96 well plates and samples were incubated for 15 minutes at $37^{\circ} \mathrm{C}$ in a water-bath. Following the compound pre-incubation 10X final IL-8 was added to appropriate wells (10 $\mu$ l of $20 \mathrm{nM}$ working stock IL-8, final IL-8 concentration in blood $=2 \mathrm{nM}$ ) and $10 \mu \mathrm{l}$ of PBS was added to the un-stimulated controls. 10X final dose response range IL-8 was also added to designated wells (final concentration range on assay plate was $200 \mathrm{nM}$ to $0.0005 \mathrm{nM}, 1: 5$ serial dilution in PBS). The IL-8 and PBS were added to appropriate wells across all assay plates in the same sequence as the blood to compound addition. Once added to all assay plates, samples were mixed quickly once to ensure even distribution of IL-8. Samples were incubated for 5 minutes at $37^{\circ} \mathrm{C}$ in a water-bath. Following the incubation sample plates were transferred to ice where $250 \mu$ of chilled Assay Fixative Buffer was added promptly to all wells. Samples were incubated on ice for 7 minutes (no mixing). Following fixation $1.2 \mathrm{ml}$ of $1 \mathrm{X}$ Lysis Solution was then added promptly to each well. Once added samples were mixed once and incubated on ice for 30 minutes to achieve uniform red blood cells lysis. After lysis, $200 \mu l$ of sample was transferred to a 96 well microplate on ice. Samples were acquired using the HTS on high throughput mode on a Becton Dickinson FACS Canto II. Granulocytes were identified based on differential side scatter (SSC) and forward scatter (FSC) characteristics. Neutrophils were distinguished from eosinophils using the phycoerythrin channel, as the latter have higher auto-fluorescence. The mean FSC value for the neutrophil population was taken as measure of cell shape change (the greater the FSC value meant the greater the degree of shape change). Data was presented as \% shape change over basal for the IL-8 dose response curve and assay window controls and presented as \% inhibition of shape change for compound treated samples.

\section{\% shape change above basal}

Subtract the un-stimulated control FSC reading from agonist FSC readings, divide results by the un-stimulated FSC value and multiply by 100 to give \% shape change above basal.

\section{\% inhibition}

$\%$ inhibition $=(X-Y) / X^{*} 100$

$\mathrm{X}=$ IL-8 FSC response minus the un-stimulated control (basal) FSC.

$\mathrm{Y}=\mathrm{IL}-8 \mathrm{FSC}$ response in compound treated samples minus the un-stimulated control (basal) FSC.

The $\%$ inhibition values were plotted on the $\mathrm{Y}$-axis against compound concentration on the $\mathrm{x}$-axis, to give $\mathrm{IC}_{50}$ values. 
PI3K $\alpha, \beta, \delta, \gamma$ isoform biochemical and cellular data for compounds 11-33

Table S2. PI3K $\alpha, \beta, \delta, \gamma$ isoform biochemical and cellular data for compounds 11-22

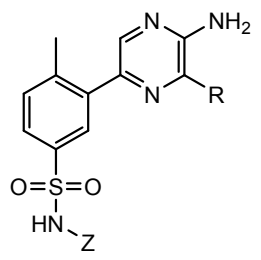

\begin{tabular}{|c|c|c|c|c|c|c|c|c|c|c|}
\hline No & $\mathrm{Z}$ & $\mathrm{R}$ & $\begin{array}{l}\gamma \mathrm{IC}_{50} \\
(\mathrm{nM})^{\mathrm{a}}\end{array}$ & $\begin{array}{l}\alpha \mathrm{IC}_{5 \mathrm{o}} \\
(\mathrm{nM})^{\mathrm{b}}\end{array}$ & $\begin{array}{l}\beta \mathrm{IC}_{5 \mathrm{o}} \\
(\mathrm{nM})^{\mathrm{b}}\end{array}$ & $\begin{array}{l}\delta \mathrm{IC}_{50} \\
(\mathrm{nM})^{\mathrm{a}}\end{array}$ & $\begin{array}{l}\text { Cell IC }_{50} \\
\gamma(\mathrm{nM})^{\mathrm{c}}\end{array}$ & $\begin{array}{l}\text { Cell IC }_{50} \\
\alpha(\mathrm{nM})^{\mathrm{d}}\end{array}$ & $\begin{array}{l}\text { Cell IC }_{50} \\
\beta(\mathrm{nM})^{\mathrm{d}}\end{array}$ & $\begin{array}{l}\text { Cell IC }_{50} \\
\delta(n M)^{\mathrm{d}}\end{array}$ \\
\hline 11 & & & 14 & 94 & 620 & 43 & 7 & 1000 & 1790 & 310 \\
\hline 12 & & & 26 & 37 & 120 & 28 & 64 & 1040 & 2670 & 1240 \\
\hline 13 & & & 13 & 35 & 890 & 55 & 24 & 680 & 3840 & 600 \\
\hline 14 & & & 9 & 169 & 9200 & 66 & 55 & 550 & 9080 & 4700 \\
\hline 15 & & & 14 & 63 & 530 & 230 & - & - & - & - \\
\hline 16 & & & 6 & 55 & 970 & 62 & 28 & 820 & 2710 & 380 \\
\hline 17 & & & 25 & 290 & 2700 & 500 & 140 & 1470 & 2200 & 660 \\
\hline 18 & & & 36 & 450 & 2000 & 910 & 350 & 4380 & 7280 & 4140 \\
\hline 19 & & & 36 & 880 & 1600 & 1300 & 240 & - & - & - \\
\hline 20 & & & 14 & 520 & 2200 & 1100 & 150 & - & - & - \\
\hline 21 & & & 28 & 200 & 1000 & 320 & 61 & $>10000$ & $>10000$ & 1500 \\
\hline 22 & & & 4 & 34 & 130 & 24 & 9 & 92 & 280 & 72 \\
\hline
\end{tabular}


Table S3. PI3K $\alpha, \beta, \delta, \gamma$ isoform biochemical and cellular data for compounds 23-33

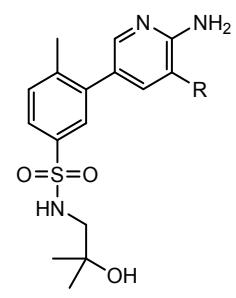

\begin{tabular}{|c|c|c|c|c|c|c|c|c|c|}
\hline & $\mathrm{R}$ & $\begin{array}{l}\gamma \mathrm{IC}_{50} \\
(\mathrm{nM})^{\mathrm{a}}\end{array}$ & $\begin{array}{l}\alpha \mathrm{IC}_{50} \\
(\mathrm{nM})^{\mathrm{b}}\end{array}$ & $\begin{array}{l}\beta \mathrm{IC}_{5 \mathrm{o}} \\
(\mathrm{nM})^{\mathrm{b}}\end{array}$ & $\begin{array}{l}\delta \mathrm{IC}_{50} \\
(\mathrm{nM})^{\mathrm{a}}\end{array}$ & $\begin{array}{c}\text { Cell } \gamma \text { IC }_{50} \\
(\mathrm{nM})^{\mathrm{c}}\end{array}$ & $\begin{array}{l}\text { Cell } \alpha \mathrm{IC}_{50} \\
(\mathrm{nM})^{\mathrm{d}}\end{array}$ & $\begin{array}{l}\text { Cell } \beta \mathrm{IC}_{50} \\
(\mathrm{nM})^{\mathrm{d}}\end{array}$ & $\begin{array}{l}\text { Cell } \delta \mathrm{IC}_{50} \\
(\mathrm{nM})^{\mathrm{d}}\end{array}$ \\
\hline 23 & & 12 & 620 & 4200 & 240 & 240 & 5920 & 8930 & 3540 \\
\hline 24 & & 1800 & 7500 & 6300 & 4850 & - & $>10000$ & 2340 & $>10000$ \\
\hline 25 & & 40 & 900 & 3800 & 5200 & 200 & 4910 & 2440 & 1600 \\
\hline 26 & & 880 & 9400 & $>10000$ & $>10000$ & - & - & - & - \\
\hline 27 & & 170 & 570 & 2700 & 1600 & 151 & $>10000$ & $>10000$ & 2200 \\
\hline 28 & & 330 & 1600 & 6600 & 1500 & - & $>10000$ & $>10000$ & $>10000$ \\
\hline 29 & & 1100 & 880 & 1500 & 5100 & - & - & - & - \\
\hline 30 & & 88 & 640 & 3400 & 570 & 400 & - & - & - \\
\hline 31 & & 66 & 1700 & $>10000$ & 1400 & 470 & - & - & - \\
\hline 32 & & 24 & 950 & 3500 & 590 & 110 & 4640 & 5260 & 1800 \\
\hline 33 & & 40 & 300 & 1700 & 730 & 120 & 6250 & 1670 & 2120 \\
\hline
\end{tabular}


$\underline{\text { Table S-4 Kinase selectivity panel assays for } 33}$

\begin{tabular}{|c|c|c|}
\hline \multirow{2}{*}{$\begin{array}{l}\text { Kinase } \\
\text { AURKA }\end{array}$} & \multicolumn{2}{|c|}{$\mathrm{IC}_{50}(\mu \mathrm{M})$} \\
\hline & $>$ & 10 \\
\hline BTK & $>$ & 10 \\
\hline FGFR4 & $>$ & 10 \\
\hline JAK2 & $>$ & 10 \\
\hline KDR & $>$ & 10 \\
\hline KIT & $>$ & 10 \\
\hline MAP3К8 & $>$ & 10 \\
\hline MKNK2 & $>$ & 10 \\
\hline PDGFRa & $>$ & 10 \\
\hline PRKCA & $>$ & 10 \\
\hline PRKCQ & $>$ & 10 \\
\hline ROCK2 & $>$ & 10 \\
\hline ZAP70 & $>$ & 10 \\
\hline ACVR1 & $>$ & 10 \\
\hline FGFR2 & $>$ & 10 \\
\hline FLT3 & & 9.2 \\
\hline GSK3B & $>$ & 10 \\
\hline IRAK1 & $>$ & 10 \\
\hline IRAK4 & $>$ & 10 \\
\hline KDR & $>$ & 10 \\
\hline
\end{tabular}




\begin{tabular}{|c|c|c|}
\hline LYN & $>$ & 10 \\
\hline MAP3K8 & $>$ & 10 \\
\hline MAP4K4 & & 1.6 \\
\hline MKNK2 & $>$ & 10 \\
\hline PDGFRa & $>$ & 10 \\
\hline ROCK2 & $>$ & 10 \\
\hline SYK nonphos & $>$ & 10 \\
\hline ABL1 nonphos & $>$ & 10 \\
\hline MAP3K7 & $>$ & 10 \\
\hline ADP-FRET PIK3CD & & 0.73 \\
\hline ADP-FRET PIK3CG & & 0.04 \\
\hline PI3Ka & & 0.3 \\
\hline PI3Kb & & 1.7 \\
\hline $\mathrm{PI} 4 \mathrm{~Kb}$ & & 2.2 \\
\hline STK17B & $>$ & 10 \\
\hline STK4 & $>$ & 10 \\
\hline VPS34 & & 7.41 \\
\hline
\end{tabular}

Table S-5 Safety pharmacology panel assays for 33

\begin{tabular}{|cc|}
\hline & $\mathrm{IC}_{50} /$ \\
Safety panel target & $\mathrm{EC}_{50} \mu \mathrm{M}$ \\
\hline
\end{tabular}




\begin{tabular}{|c|c|c|}
\hline $5 \mathrm{HTT}$ & $>$ & 30 \\
\hline Ad1 (A1) & $>$ & 30 \\
\hline $\mathrm{Ad} 2 \mathrm{a}(\mathrm{A} 2 \mathrm{~A})$ & $>$ & 30 \\
\hline Ad3 & $>$ & 30 \\
\hline AdT (AoT) & $>$ & 30 \\
\hline Alpha1a & $>$ & 30 \\
\hline Alpha1a & $>$ & 30 \\
\hline Alpha2a & $>$ & 30 \\
\hline Alpha2b & $>$ & 30 \\
\hline Alpha2c & $>$ & 30 \\
\hline$A R$ & $>$ & 30 \\
\hline AT1 & $>$ & 30 \\
\hline Beta1 & $>$ & 30 \\
\hline Beta2 & $>$ & 30 \\
\hline BZD & $>$ & 30 \\
\hline CB1 & $>$ & 30 \\
\hline CCK1 & $>$ & 30 \\
\hline cox1 & $>$ & 30 \\
\hline cox2 & $>$ & 30 \\
\hline D1 & & 25 \\
\hline $\mathrm{D} 2 \mathrm{~L}$ & $>$ & 30 \\
\hline D3 & $>$ & 30 \\
\hline
\end{tabular}




\begin{tabular}{|c|c|c|}
\hline DAT & $>$ & 30 \\
\hline ERalpha & $>$ & 30 \\
\hline ETa & $>$ & 30 \\
\hline GABAA & $>$ & 30 \\
\hline GHS & $>$ & 30 \\
\hline GR & $>$ & 30 \\
\hline $\mathrm{H} 1$ & $>$ & 30 \\
\hline $\mathrm{H} 3$ & $>$ & 30 \\
\hline M1 & $>$ & 30 \\
\hline M2 & $>$ & 30 \\
\hline M2 & $>$ & 30 \\
\hline M3 & $>$ & 30 \\
\hline MAO-A & $>$ & 30 \\
\hline MC3 & $>$ & 30 \\
\hline Motilin & $>$ & 30 \\
\hline NET & $>$ & 30 \\
\hline Nins & $>$ & 30 \\
\hline OpD & $>$ & 30 \\
\hline OpM & $>$ & 30 \\
\hline PDE3 & $>$ & 30 \\
\hline PDE4d2 & & 1.1 \\
\hline PPARgamma & $>$ & 30 \\
\hline
\end{tabular}




$\left|\begin{array}{lll}\text { PR-B } & > & 30 \\ \text { PXR } & > & 30 \\ \text { V1a } & > & 30 \\ \text { BSEP } & & 52\end{array}\right|$

Table S-6 single concentration safety pharmacology assays (Eurofins Panlabs)

Biochemical assay results are presented as the percent inhibition of specific binding or activity

\begin{tabular}{|l|l|l|l|l|l|}
\hline Cat \# Assay Name & Species & Rep. & Conc. & $\%$ & Inh. \\
\hline 107710 ATPase, Na+/K+, Heart & pig & 2 & 10 & $\mu \mathrm{M}$ & -9 \\
\hline 123980 Deacetylase, Sirtuin SIRT6 & hum & 2 & 10 & $\mu \mathrm{M}$ & -3 \\
\hline 137010 Lipoxygenase 12-LO & hum & 2 & 10 & $\mu \mathrm{M}$ & -6 \\
\hline 136020 Lipoxygenase 5-LO & hum & 2 & 10 & $\mu \mathrm{M}$ & 10 \\
\hline $\begin{array}{l}\text { 191000 Protein Tyrosine Phosphatase, PTEN } \\
\text { (MMAC1) }\end{array}$ & hum & 2 & 10 & $\mu \mathrm{M}$ & 3 \\
\hline $\begin{array}{l}\text { 192910 Protein Tyrosine Phosphatase, PTPN11 } \\
\text { (SHP-2) }\end{array}$ & hum & 2 & 10 & $\mu \mathrm{M}$ & -8 \\
\hline $\begin{array}{l}\text { 192210 Protein Tyrosine Phosphatase, PTPN6 } \\
\text { (PTP1C, SHP-1) }\end{array}$ & hum & 2 & 10 & $\mu \mathrm{M}$ & -19 \\
\hline $\begin{array}{l}\text { 194020 Thromboxane Synthase } \\
\text { 210120 Angiotensin AT2 }\end{array}$ & hum & 2 & 10 & $\mu \mathrm{M}$ & 1 \\
\hline 210710 APJ & hum & 2 & 10 & $\mu \mathrm{M}$ & -2 \\
\hline 211600 Bombesin BB1 & 2 & 10 & $\mu \mathrm{M}$ & -1 \\
\hline 211700 Bombesin BB2 & 2 & 10 & $\mu \mathrm{M}$ & 2 \\
\hline
\end{tabular}




\begin{tabular}{|c|c|c|c|c|c|}
\hline 211800 Bombesin BB3 & hum & 2 & 10 & $\mu \mathrm{M}$ & 2 \\
\hline 212510 Bradykinin B1 & hum & 2 & 10 & $\mu \mathrm{M}$ & 4 \\
\hline 212620 Bradykinin B2 & hum & 2 & 10 & $\mu \mathrm{M}$ & -6 \\
\hline 217100 Cannabinoid CB2 & hum & 2 & 10 & $\mu \mathrm{M}$ & 10 \\
\hline 217510 Chemokine CCR1 & hum & 2 & 10 & $\mu \mathrm{M}$ & -6 \\
\hline 217550 Chemokine CCR2B & hum & 2 & 10 & $\mu \mathrm{M}$ & -6 \\
\hline 217660 Chemokine CCR4 & hum & 2 & 10 & $\mu \mathrm{M}$ & 11 \\
\hline 217720 Chemokine CCR5 & hum & 2 & 10 & $\mu \mathrm{M}$ & -4 \\
\hline 244500 Chemokine CXCR2 (IL-8RB) & hum & 2 & 10 & $\mu \mathrm{M}$ & -4 \\
\hline 218130 Cholecystokinin CCK2 (CCKB) & hum & 2 & 10 & $\mu \mathrm{M}$ & 4 \\
\hline 220000 Dopamine D4.4 & hum & 2 & 10 & $\mu \mathrm{M}$ & -1 \\
\hline 224110 Endothelin ETB & hum & 2 & 10 & $\mu \mathrm{M}$ & 3 \\
\hline 226050 Estrogen ERß & hum & 2 & 10 & $\mu \mathrm{M}$ & 13 \\
\hline 226810 GABAA, Chloride Channel, TBOB & rat & 2 & 10 & $\mu \mathrm{M}$ & 18 \\
\hline 231510 Galanin GAL1 & hum & 2 & 10 & $\mu \mathrm{M}$ & 21 \\
\hline 231680 Glucagon & hum & 2 & 10 & $\mu \mathrm{M}$ & 2 \\
\hline 232600 Glutamate, AMPA & rat & 2 & 10 & $\mu \mathrm{M}$ & 14 \\
\hline 232700 Glutamate, Kainate & rat & 2 & 10 & $\mu \mathrm{M}$ & -3 \\
\hline 232810 Glutamate, NMDA, Agonism & rat & 2 & 10 & $\mu \mathrm{M}$ & 6 \\
\hline 232910 Glutamate, NMDA, Glycine & rat & 2 & 10 & $\mu \mathrm{M}$ & 13 \\
\hline 233000 Glutamate, NMDA, Phencyclidine & rat & 2 & 10 & $\mu \mathrm{M}$ & -19 \\
\hline
\end{tabular}




\begin{tabular}{|c|c|c|c|c|c|}
\hline 234000 Glutamate, NMDA, Polyamine & rat & 2 & 10 & $\mu \mathrm{M}$ & 5 \\
\hline 239000 Glycine, Strychnine-Sensitive & rat & 2 & 10 & $\mu \mathrm{M}$ & -26 \\
\hline 239200 Gonadotropin-Releasing Hormone & hum & 2 & 10 & $\mu \mathrm{M}$ & -1 \\
\hline 239900 Histamine $\mathrm{H} 4$ & hum & 2 & 10 & $\mu \mathrm{M}$ & -1 \\
\hline 241000 Imidazoline I2, Central & rat & 2 & 10 & $\mu \mathrm{M}$ & 18 \\
\hline 242500 Inositol Trisphosphate IP3 & rat & 2 & 10 & $\mu \mathrm{M}$ & -5 \\
\hline 250510 Leukotriene, BLT (LTB4) & hum & 2 & 10 & $\mu \mathrm{M}$ & -6 \\
\hline 250460 Leukotriene, Cysteinyl CysLT1 & hum & 2 & 10 & $\mu \mathrm{M}$ & 2 \\
\hline 250480 Leukotriene, Cysteinyl CysLT2 & hum & 2 & 10 & $\mu \mathrm{M}$ & 1 \\
\hline 251100 Melanocortin MC1 & hum & 2 & 10 & $\mu \mathrm{M}$ & 0 \\
\hline 251400 Melanocortin MC5 3 & hum & 2 & 10 & $\mu \mathrm{M}$ & 18 \\
\hline 251600 Melatonin MT1 & hum & 2 & 10 & $\mu \mathrm{M}$ & -2 \\
\hline 251700 Melatonin MT2 & hum & 2 & 10 & $\mu \mathrm{M}$ & 3 \\
\hline 252910 Muscarinic M4 & hum & 2 & 10 & $\mu \mathrm{M}$ & 5 \\
\hline 253010 Muscarinic M5 & hum & 2 & 10 & $\mu \mathrm{M}$ & -11 \\
\hline 256100 Neuromedin U NMU1 & hum & 2 & 10 & $\mu \mathrm{M}$ & 11 \\
\hline 256200 Neuromedin U NMU2 & hum & 2 & 10 & $\mu \mathrm{M}$ & -1 \\
\hline 257010 Neuropeptide Y Y1 & hum & 2 & 10 & $\mu \mathrm{M}$ & -5 \\
\hline 258010 Neurotensin NT1 & hum & 2 & 10 & $\mu \mathrm{M}$ & 2 \\
\hline 258700 Nicotinic Acetylcholine $\alpha 1$, Bungarotoxin & hum & 2 & 10 & $\mu \mathrm{M}$ & 0 \\
\hline 260700 Orexin OX1 & hum & 2 & 10 & $\mu \mathrm{M}$ & -6 \\
\hline
\end{tabular}




\begin{tabular}{|c|c|c|c|c|c|}
\hline 260900 Oxytocin & hum & 2 & 10 & $\mu \mathrm{M}$ & 6 \\
\hline 265010 Platelet Activating Factor (PAF) & hum & 2 & 10 & $\mu \mathrm{M}$ & 20 \\
\hline 265500 Potassium Channel [KA] & rat & 2 & 10 & $\mu \mathrm{M}$ & -3 \\
\hline 268030 Prostanoid CRTH2 & hum & 2 & 10 & $\mu \mathrm{M}$ & 1 \\
\hline 268060 Prostanoid DP & hum & 2 & 10 & $\mu \mathrm{M}$ & -3 \\
\hline 268110 Prostanoid EP1 & hum & 2 & 10 & $\mu \mathrm{M}$ & 26 \\
\hline 268200 Prostanoid EP2 & hum & 2 & 10 & $\mu \mathrm{M}$ & 7 \\
\hline 268310 Prostanoid EP3 & hum & 2 & 10 & $\mu \mathrm{M}$ & -3 \\
\hline 268420 Prostanoid EP4 & hum & 2 & 10 & $\mu \mathrm{M}$ & 3 \\
\hline 268510 Prostanoid FP & hum & 2 & 10 & $\mu \mathrm{M}$ & -20 \\
\hline 268600 Prostanoid IP & hum & 2 & 10 & $\mu \mathrm{M}$ & -3 \\
\hline 270300 Ryanodine RyR3 & rat & 2 & 10 & $\mu \mathrm{M}$ & 15 \\
\hline 272000 Serotonin (5-Hydroxytryptamine) 5-HT4 & gp & 2 & 10 & $\mu \mathrm{M}$ & 11 \\
\hline 272200 Serotonin (5-Hydroxytryptamine) 5-HT6 & hum & 2 & 10 & $\mu \mathrm{M}$ & 6 \\
\hline 272320 Serotonin (5-Hydroxytryptamine) 5-HT7 & hum & 2 & 10 & $\mu \mathrm{M}$ & 2 \\
\hline 278110 Sigma $\sigma 1$ & hum & 2 & 10 & $\mu \mathrm{M}$ & 6 \\
\hline 282510 Somatostatin sst1 & hum & 2 & 10 & $\mu \mathrm{M}$ & 1 \\
\hline 282530 Somatostatin sst3 & hum & 2 & 10 & $\mu \mathrm{M}$ & -5 \\
\hline 283010 Somatostatin sst5 & hum & 2 & 10 & $\mu \mathrm{M}$ & -5 \\
\hline 255710 Tachykinin NK3 & hum & 2 & 10 & $\mu \mathrm{M}$ & -8 \\
\hline 286010 Thyrotropin Releasing Hormone (TRH) & hum & 2 & 10 & $\mu \mathrm{M}$ & 3 \\
\hline
\end{tabular}




\begin{tabular}{|l|l|l|l|l|l|}
\hline 219000 Transporter, Choline & rat & 2 & 10 & $\mu \mathrm{M}$ & -1 \\
\hline 226400 Transporter, GABA & rat & 2 & 10 & $\mu \mathrm{M}$ & 8 \\
\hline 286510 Tumor Necrosis Factor (TNF), Non-Selective & hum & 2 & 10 & $\mu \mathrm{M}$ & -1 \\
\hline 286700 Urotensin II & hum & 2 & 10 & $\mu \mathrm{M}$ & 0 \\
\hline 287010 Vasoactive Intestinal Peptide VIP1 & hum & 2 & 10 & $\mu \mathrm{M}$ & 5 \\
\hline 287610 Vasopressin V2 & hum & 2 & 10 & $\mu \mathrm{M}$ & 8 \\
\hline 288010 Vitamin D3 & hum & 2 & 10 & $\mu \mathrm{M}$ & -7 \\
\hline
\end{tabular}

\section{KinomeScan ${ }^{\circledR}$ Treespot ${ }^{\mathrm{TM}}$ interaction map for example 33}

The KINOMEscan ${ }^{\mathrm{TM}}$ screening platform employs a novel and proprietary active site-directed competition binding assay to quantitatively measure interactions between test compounds and more than 450 human kinases and disease relevant mutant variants. This robust and reliable assay technology affords investigators the ability to extensively annotate compounds with accurate, precise and reproducible data. KINOMEscan ${ }^{\mathrm{TM}}$ assays do not require ATP and thereby report true thermodynamic interaction affinities, as opposed to IC50 values, which can depend on the ATP concentration.

References: For a more detailed description of KINOMEscan's assay technology, see:

- Fabian et al. A small molecule-kinase interaction map for clinical kinase inhibitors. Nat. Biotechnol. 23, 329-336 (2005). 


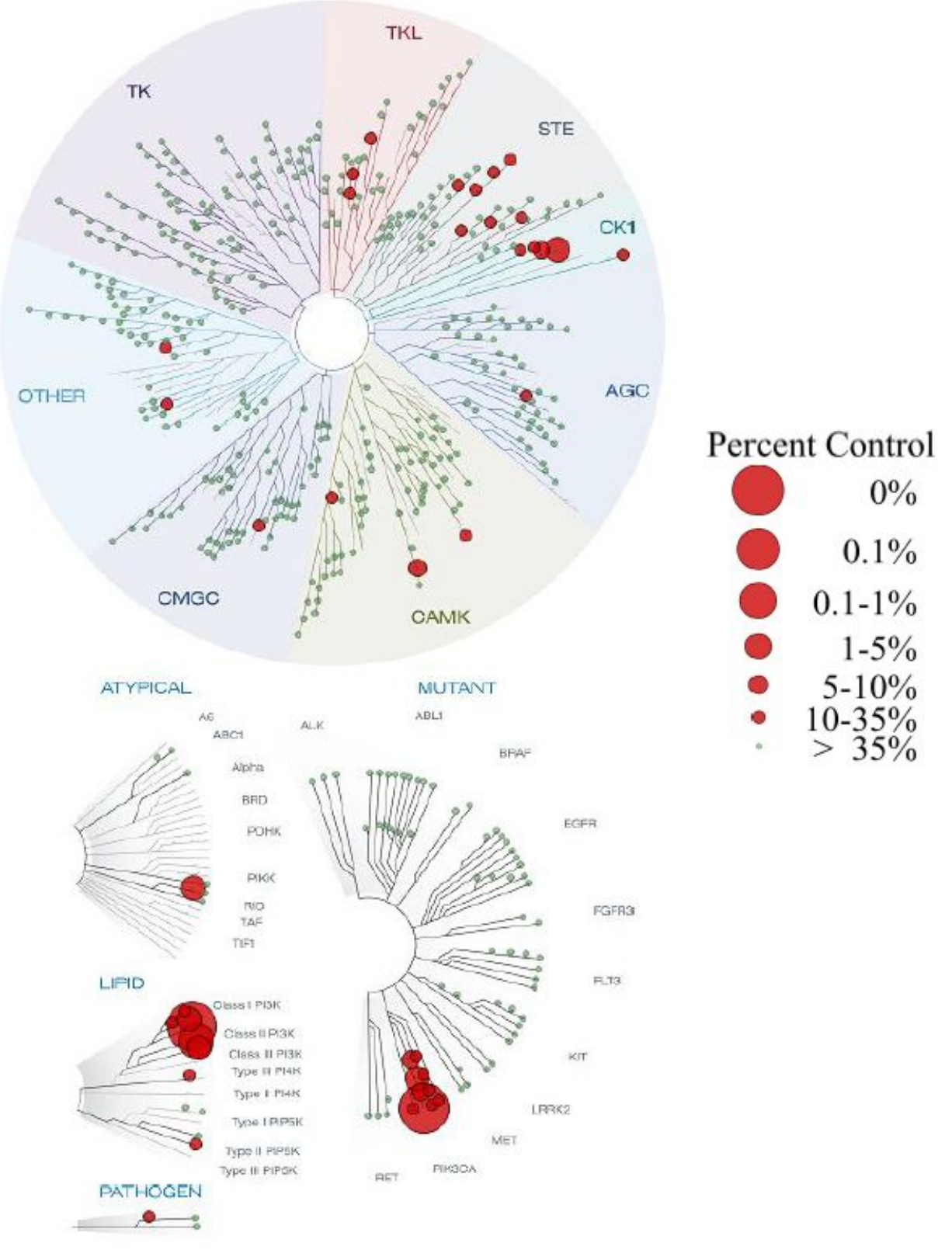

Figure S-1 KinomeScan® Treespot ${ }^{\mathrm{TM}}$ interaction map for example 33

\section{Selectivity Score (S-scores)}

Selectivity Score or S-score is a quantitative measure of compound selectivity. It is calculated by dividing the number of kinases that compounds bind to by the total number of distinct kinases tested, excluding mutant variants.

$S=$ Number of hits $/$ Number of assays

This value can be calculated using \%Ctrl as a potency threshold (below) and provides a quantitative method of describing compound selectivity to facilitate comparison of different compounds. 
$\mathrm{S}(35)=($ number of non-mutant kinases with $\% \mathrm{Ctrl}<35) /($ number of non-mutant kinases tested $)$

$S(10)=($ number of non-mutant kinases with \%Ctrl $<10) /($ number of non-mutant kinases tested $)$

$S(1)=($ number of non-mutant kinases with $\% C \operatorname{ctrl}<1) /($ number of non-mutant kinases tested $)$

Table S-7 Selectivity score for compound 33

\begin{tabular}{|l|l|l|l|l|}
\hline Selectivity Score Type & Number of Hits & Number of Non-Mutant Kinases & Screening Concentration (nM) & Selectivity Score \\
\hline S(35) & 31 & 395 & 10000 & 0.078 \\
\hline S(10) & 8 & 395 & 10000 & 0.02 \\
\hline$S(1)$ & 2 & 395 & 10000 & 0.005 \\
\hline
\end{tabular}

\section{ADME Assays}

\section{Microsomal clearance assay}

The experiments were performed in 96 -well glass plates at $37^{\circ} \mathrm{C}$ on an automated Tecan EVO platform. Test compounds at a concentration of $10 \mathrm{mM}$ in pure DMSO were diluted 1:1000 in water to $10 \mu \mathrm{M}$. This solution $(30 \mu \mathrm{L})$ was added to $120 \mu \mathrm{L}$ of rat liver microsomal protein $(1.25 \mathrm{mg} / \mathrm{mL})$ suspended in phosphate buffer ( $\mathrm{pH}$ 7.4). Reactions were initiated by the addition of $150 \mu \mathrm{L}$ of a cofactor solution containing $2 \mathrm{mM}$ NADPH. At specific reaction time points $(0,5,20$, and $30 \mathrm{~min})$, aliquots $(50 \mu \mathrm{L})$ were removed and reactions were terminated by the addition to acetonitrile $(100 \mu \mathrm{L})$ containing the analytical internal standards ( $1 \mu \mathrm{M}$ alprenolol and $1.6 \mu \mathrm{M}$ chlorzoxazone) and stored at $-20^{\circ} \mathrm{C}$ for at least $1 \mathrm{~h}$ to allow complete precipitation of proteins. The samples were then centrifuged at $5000 \mathrm{~g}$ at $4{ }^{\circ} \mathrm{C}$ for $35 \mathrm{~min}$, and $20 \mu \mathrm{L}$ of the supernatants were analyzed by LC-MS/MS for quantitation of the remaining test article. The percentage of test compound remaining, relative to time zero minute incubation, is used to estimate the in vitro elimination-rate constant $\left(k_{\text {mic }}\right)$, which is used to calculate the in vitro metabolic clearance rates.

\section{High-throughput equilibrium solubility}

Sample preparation for high-throughput equilibrium solubility determination was performed in microtiter plate format. Starting from $10 \mathrm{mM}$ DMSO stock solution, each sample was dispensed in triplicates. The DMSO was evaporated in an evaporator (Combidancer, Hettich) under vacuum and moderate heat of 35 ${ }^{\circ} \mathrm{C}$. Afterwards the buffer media was added, the plate sealed and shaken overnight at $1000 \mathrm{rpm}$ (Tritrimax, Heidolph) at ambient temperature. After phase separation of supernatant and undissolved solid by centrifugation, an adequate volume of the supernatant was diluted for analysis. Quantitation was done using a four point external calibration curve, performed by mass spectrometry using LCMS/ MS (TSQ Discovery, Thermo). Data evaluation was performed by Excel (Microsoft) and results were stored in a proprietary laboratory information system. 


\section{Thermodynamic solubility (saturation shake flask method)}

$0.5 \mathrm{~mL}$ of pH6.8 buffer is added to ca. $2 \mathrm{mg}$ of sample in a small borosilicate vial $(2 \mathrm{~mL})$ and sonicated for 3 minutes using a sonicating bath. The suspension is then incubated at $25.0^{\circ} \mathrm{C}$ for 20 hours in a water bath at a shaking speed of $200 \mathrm{rpm}$. The phases are then separated by decantation using an Eppendorf 5414 lab-bench centrifuge. The suspension is transferred to an Eppendorf tube and centrifuged for 10 minutes. 30-50 ul of the supernatant is carefully collected and the solute quantified using an analytical method with a 7-point calibration curve of the sample diluted in methanol. Before each injection, a blank is collected (injection of $2 \mu \mathrm{l}$ of water or $\mathrm{MeOH}$ ) to avoid phantom peaks due to carry-over or impurities present in the system.

\section{PAMPA Assay}

Prepare a $1 \%$ solution $(\mathrm{w} / \mathrm{v})$ of lecithin in dodecane $(\sim 500 \mu \mathrm{L} /$ plate $)$ and sonicate the mixture to ensure complete dissolution. Carefully pipette $5 \mu \mathrm{L}$ of the lecithin/dodecane mixture into each Donor plate well, avoiding pipette tip contact with the membrane. Note: use polypropylene reservoir. Immediately after the application of the artificial membrane, add $150 \mu \mathrm{L}$ of drug-containing donor solutions (drugs dissolved in $5 \%$ DMSO, PBS) to each well of the Donor plate (in the experiments described in this Application Note, the testosterone donor concentration was $100 \mu \mathrm{M}$. All other drugs were added at a concentration of 500 $\mu \mathrm{M}$ ). Add $300 \mu \mathrm{L}$ of buffer (5\% DMSO in PBS, $\mathrm{pH} 7.4$ ) to each well of the PTFE Acceptor plate (MSSACCEPTOR or MATRNPS50).Place the drug-filled Donor plate into the Acceptor plate, making sure the underside of the membrane is in contact with the buffer. Replace plate lid and incubate at room temperature for 16 hours. Note: place the assembled plate into a sealed container with wet paper towels to avoid evaporation. After incubation, measure UV/Vis absorption from 250 to $500 \mathrm{~nm}$ for $100 \mu \mathrm{L} /$ well of the donor solution and $250 \mu \mathrm{L} /$ well of the acceptor solution. Make up drug solutions at the theoretical equilibrium concentration (i.e., the resulting concentration if the donor and acceptor solutions were simply combined) and measure UV/Vis absorption from 250 to $500 \mathrm{~nm}$ for $250 \mu \mathrm{L} /$ well of each.

Papp $=(d Q / d t) \times(1 / C 0) \times(1 / A)$

$\%$ Recovery $=$ (Total compound mass in donor and receiver compartments at the end of the incubation /Initial compound mass in the donor compartment) $\times 100$

Note: $d Q / d t$ is the permeability rate, $C 0$ is the initial concentration in the donor compartment, and $A$ is the surface area of the membrane. 


\title{
CYP Inhibition
}

\author{
IC50 $[\mu \mathrm{M}]$ \\ CYP3A4 (Midazolam) $>50$ \\ CYP2D6 (Bufuralol) > 50 \\ CYP2C9 (Diclofenac) 15.1
}

\section{$\underline{\text { Animal studies }}$}

\section{General}

All aspects of animal care, use, and welfare for research animals used for in vivo studies were performed in compliance with local governmental regulations. Furthermore, all animals were handled in accordance with Novartis Animal Care and Use Committee approved protocols and regulations.

\section{Pharmacokinetic studies in rats}

Female wild-type Sprague Dawley rats (Iffa Credo, France) were kept in standard cages and conditions according to Swiss Animal Welfare guidelines (12h light/dark cycles, RT at $22-24{ }^{\circ} \mathrm{C}$, humidity at least 45 $\%$ but $<70 \%$ ) with free access to Ringer solution (glucose $5 \%, \mathrm{NaCl} 0.9 \%$ and $\mathrm{KCl} 0.5 \%$ ) and pelleted rodent chow. 96-120 hours before administration of the test substance the animals were anesthetized with isoflurane and catheters were surgically implanted under aseptic precautions (use of sterile instruments and surgical material in combination with local antibiotic prophylaxis) into the femoral artery and vein. The catheters were exteriorized in the neck region, connected to a Harvard swivel system (Harvard Instruments) and filled with $0.9 \%$ saline containing $100 \mathrm{U} \cdot \mathrm{mL}-1$ heparin. After recovery from anesthesia the animals were housed individually in special cages with free access to food and tap water until and throughout the experiment. Analgesic treatment with Temgesic (10 $\mu \mathrm{g} / \mathrm{kg}$ s.c., application volume $1 \mathrm{~mL} / \mathrm{kg}$ ) was performed in the evening following surgery and in the next morning. Compound administration was in the morning (6-8 AM). Blood samples were collected at various time points from the femoral artery catheter into Eppendorf tubes coated with sodium EDTA. Blood samples were immediately frozen at $-20^{\circ} \mathrm{C}$ until final processing (maximum storage was 8 days). Intravenous and oral dosing was performed in the same animals after a $48 \mathrm{~h}$ wash-out interval between the single dose applications. The test substance was administered intravenously as a solution in 1-methyl-2-pyrrolidone and polyethylene glycol $200(30: 70, \mathrm{v} / \mathrm{v})$ at a dose of $1 \mathrm{mg} / \mathrm{kg}$ and orally as a homogenous aqueous suspension in Tween 80 and carboxy methyl cellulose sodium 0.5/0.5/99 (w/w) at a dose of $3 \mathrm{mg} / \mathrm{kg}$.

\section{Bioanalytical method for pharmacokinetics}

Blood samples were spiked with a structurally closely related internal standard, then lysed and deproteinated using acetonitrile. After centrifugation the supernatant was evaporated to dryness. The 
remainder was re-dissolved in methanol $(60 \%)$ and $1 \%$ aqueous formic acid $(\mathrm{pH} 3.0)$. The solution (rat and dog samples) was separated on a Synergi Polar-RP HPLC column (particle size: $2.5 \mu \mathrm{m}$; column dimensions: $2 \times 50 \mathrm{~mm}$ ) using a linear gradient (0 min, $98 \%$ A/2\% B; $0.5 \mathrm{~min}, 98 \% \mathrm{~A} / 2 \% \mathrm{~B} ; 5 \mathrm{~min}, 10 \%$ $\mathrm{A} / 90 \% \mathrm{~B} ; 5.01 \mathrm{~min}, 0 \% \mathrm{~A} / 100 \% \mathrm{~B} ; 5.5 \mathrm{~min}, 0 \% \mathrm{~A} / 100 \% \mathrm{~B}$ at a flow rate of 0.35 or $0.40 \mathrm{~mL} / \mathrm{min}$. Mobile phase $A$ consisted of $1 \%$ formic acid in HPLC grade water. Mobile phase $B$ consisted of $1 \%$ formic acid in HPLC grade acetonitrile. The flow from the HPLC system was directly introduced into the ion source of a TSQ Quantum mass spectrometer (ThermoFisher Scientific, Massachusetts, USA) and subjected to electrospray ionization (positive ion mode). The solution (monkey samples) was separated on a Synergi Hydro RP HPLC column (particle size: $2.5 \mu \mathrm{m}$; column dimensions: $2 \times 50 \mathrm{~mm}$ ) using a linear gradient $(0$ $\min , 95 \% \mathrm{~A} / 5 \% \mathrm{~B} ; 4 \mathrm{~min}, 10 \% \mathrm{~A} / 90 \% \mathrm{~B} ; 4.1 \mathrm{~min}, 2 \% \mathrm{~A} / 98 \% \mathrm{~B} ; 5.1 \mathrm{~min}, 2 \% \mathrm{~A} / 98 \% \mathrm{~B}$ at a flow rate of 0.40 or $0.45 \mathrm{~mL} / \mathrm{min}$. Mobile phase A consisted of $1 \%$ formic acid in HPLC grade water. Mobile phase $B$ consisted of $1 \%$ formic acid in HPLC grade methanol. The flow from the HPLC system was directly introduced into the ion source of a Sciex QTRAP 5500 mass spectrometer (Sciex, Massachusetts, USA) and subjected to electrospray ionization (positive ion mode). The test substance was detected via a specific daughter ion of its protonated quasi-molecular ion. Quantitation of blood levels of the test substance was based on an 8-level calibration curve (in triplicate) using blank rat blood samples spiked with stock solutions of external and internal standards. 
Figure S-2 Solution vs suspension for 16

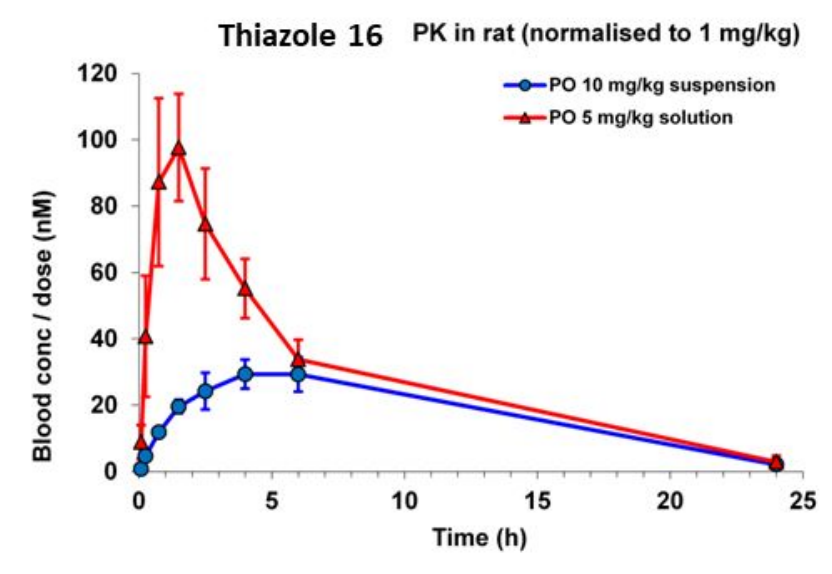

Table S-6 Rat oral PK profiles for thiazole 16. Comparison of $10 \mathrm{mpk}$ suspension dosing with $5 \mathrm{mpk}$ solution dosing.

\begin{tabular}{|l|l|l|l|l|}
\hline formulation & dose & $\begin{array}{l}\text { AUClast } \\
\text { (nM·h/L) }\end{array}$ & \%F & $\begin{array}{l}\text { AUClast (nM.h/L) dose } \\
\text { normalized to 1mg/kg }\end{array}$ \\
\hline $\begin{array}{l}\text { Suspension 0.5\% methyl cellulose, } \\
\text { o.5\% Tween 80 }\end{array}$ & $10 \mathrm{mg} / \mathrm{kg}$ & 4354 & $16 \%$ & 435 \\
\hline $\begin{array}{l}\text { Solution in PEG } \\
\text { 400:10\%VitETPGS:1\%SLS (20:40:40) }\end{array}$ & $5 \mathrm{mg} / \mathrm{kg}$ & 3650 & $27 \%$ & 730 \\
\hline
\end{tabular}

Table S-8 Rat exposures for thiazole 16. Comparison of $10 \mathrm{mpk}$ suspension dosing with $5 \mathrm{mpk}$ solution dosing.

\section{In vivo pharmacology studies}

The aim of this study was to assess the efficacy of 33 on inhibiting Ovalbumin Induced Early Airway Response phase (E.A.R) by Whole Body Plethysmography and lung inflammation in Ovalbumin Sensitized Brown Norway rat.

Two doses of compound 33, administered in $0.5 \%$ methylcellulose $0.5 \%$ tween 80 vehicle b.i.d (10 \& $20 \mathrm{mg} / \mathrm{kg}$ ) were compared against a vehicle and an active control of Dexamethasone $(3 \mathrm{mg} / \mathrm{kg}$ administered in distilled water).

Detail of experiment:

Day 0: $0.25 \mathrm{ml}$ of OVA (10ug)/Alum (30mg/ml) administered s.c. to groups 1 - 14

Day 15: $0.25 \mathrm{ml}$ of OVA (10ug)/Alum $(30 \mathrm{mg} / \mathrm{ml})$ administered s.c. to groups 1 - 14 
Day 22: $0.25 \mathrm{ml}$ of OVA (10ug)/Alum (30mg/ml) administered s.c. to Groups 1 - 14

Day 28: rats transferred to B95 Scantainers. Approx 30 mins prior to being challenged the animals well be dosed p.o. as follows: Groups 1 \& 2 vehicle p.o., Group 3 compound 33 10mg/kg p.o., Group 4 compound 33 20mg/kg p.o., Group 5 Dexamethasone 3mg/kg, Group 6 compound 33 10mg/kg p.o., Group 7 compound $3320 \mathrm{mg} / \mathrm{kg}$ p.o. Animals from Group $6 \& 7$ were bled from the tail vein at selected time points during the day and at 24-hours post dose. Groups 1-5 were challenged for $20 \mathrm{mins}$ via Aeroneb nebulized solution as follows: PSA Aerosol Group 1, 1\% OVA Aerosol Groups 2-5. Following the Aerosol challenge the animals remained housed in the WBP with access to food and water while respiratory measurements were recorded up to 6.5 hours or until parameters returned to baseline. Once the recording has finished the animals will be dosed as follows Groups $1 \& 2$ Vehicle p.o., group 3 compound $3310 \mathrm{mg} / \mathrm{kg}$ p.o., group 4 compound $3320 \mathrm{mg} / \mathrm{kg}$ p.o., group 6 compound $3310 \mathrm{mg} / \mathrm{kg}$ p.o., group 7 compound $3320 \mathrm{mg} / \mathrm{kg}$ p.o. prior to being singly housed in fresh cages within a Scantainer in the stock room. Under no circumstances should the animals be returned to the group housing.

Day 29: Approx 24 hours following either PBS or 1\% OVA challenge selected animals were bled from the vein or under anesthesia (overdose of $100 \mathrm{mg} / \mathrm{ml}$ pentobarbitone) prior to schedule 1 being confirmed. Once schedule 1 was confirmed the animals had their lungs lavaged. The lungs may be removed for histological examination or PK analysis. BALF will be analyzed for inflammatory cells using the Sysmex XT1800V. Groups 1-5, Groups 6 \& 7 PK and lungs only.

Day 30: Rats were transferred to B95 in Scantainers. Aprrox 30mins prior to being challenged the animals were dosed p.o. as follows: Groups 8 \& 9 vehicle p.o., Group 10 compound 33 10mg/kg p.o., Group 11 compound 33 20mg/kg p.o., Group 12 Dexamethasone 3mg/kg, Group 13 compound 33 10mg/kg p.o., Group 14 compound $3320 \mathrm{mg} / \mathrm{kg}$ p.o. Animals from Group $13 \& 14$ were bled from the tail vein at selected time points during the day and at 24-hours post dose. Groups 8-12 were challenged for 20mins via Aeroneb nebulized solution as follows: PSA Aerosol Group 8, 1\% OVA Aerosol Groups 9-12.

Following the Aerosol challenge the animals remained housed in the WBP with access to food and water while respiratory measurements were recorded up to 6.5 hours or until parameters returned to baseline. Once the recording has finished the animals will be dosed as follows Groups 8 \& 9 Vehicle p.o., group 10 compound 33 10mg/kg p.o., group 11 compound 33 20mg/kg p.o., group 13 compound 33 10mg/kg p.o., group 14 compound $3320 \mathrm{mg} / \mathrm{kg}$ p.o. prior to being singly housed in fresh cages within a Scantainer in the stock room. Under no circumstances should the animals be returned to the group housing.

Day 31: Approx 24 hours following either PBS or 1\% OVA challenge selected animals were bled from the vein or under anesthesia (overdose of $100 \mathrm{mg} / \mathrm{ml}$ pentobarbitone) prior to schedule 1 being confirmed. Once schedule 1 was confirmed the animals had their lungs lavaged. The lungs may be removed for histological examination or PK analysis. BALF will be analyzed for inflammatory cells using the Sysmex XT1800V. Groups 8-12, Groups 13 \& 14 PK and lungs only.

\section{Preparation of Aluminum hydroxide adjuvant \& OVA for groups 1-14.}


Prepare $10 \%$ potassium alum (aluminum potassium sulphate, $\mathrm{AlK}\left(\mathrm{SO}_{4}\right)_{2} \cdot \mathrm{H}_{2} \mathrm{O}$ ) in distilled water. In a $50 \mathrm{ml}$ conical tube, add $10 \mathrm{ml}$ of $10 \%$ aluminum. Whilst slowly vortexing, add $22.8 \mathrm{ml} 0.25 \mathrm{M} \mathrm{NaOH}$ dropwise. Incubate at room temperature for 10 mins. Centrifuge at $1000 \mathrm{~g}$ for $10 \mathrm{mins}$. Discard supernatant and wash with $50 \mathrm{ml}$ distilled water. Re-suspend in $33 \mathrm{ml}$ PBS for $30 \mathrm{mg} / \mathrm{ml}$ alum.

Make a $1 \mathrm{mg} / \mathrm{ml}$ OVA (sigma, A5503) solution in PBS. Then dilute 1:20 into alum (1 $\mathrm{ml}$ in to $19 \mathrm{ml}$ ) before rolling for minimum of 4 hours prior to dosing.

Immunize rats in Groups 1-14 as follows:

OVA/Alum, Alternate site: $0.2 \mathrm{ml}$ between shoulders $1^{\text {st }}$ injection, right hip $2^{\text {nd }}$ injection \& left hip injection.

Preparation of 1\% OVA for challenge Groups 2-5 and 9-12.

For $1 \%$ challenge, prepare $0.5 \mathrm{~g}$ in $50 \mathrm{ml}$ PBS.

$9 \mathrm{ml}$ of fresh OVA is required to fill the nebulizer for each $20 \mathrm{~min}$ challenge.

\section{Collection of blood, BAL and lung samples}

Whole blood may be collected into EDTA blood tubes and frozen for PK analysis.

Bronchoalveolar lavage performed within $3 \times 4 \mathrm{ml}$ PBS washes, then centrifuged at 1200rpm for 10min. BAL supernatant will be collected then stored at $-80 \circ \mathrm{C}$. Cells will be re-suspended in $1 \mathrm{ml}$ PBS and automatically counted and differentiated by Sysmex XT-1800i. The lungs may be either frozen in liquid nitrogen or insuflated and stored in formalin for histological examination

\section{LCMS purity data for final compounds}

\section{Compound 9}

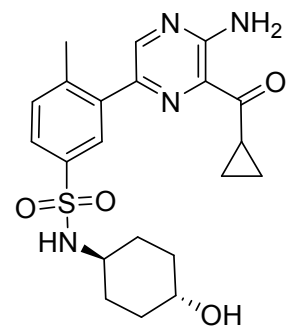




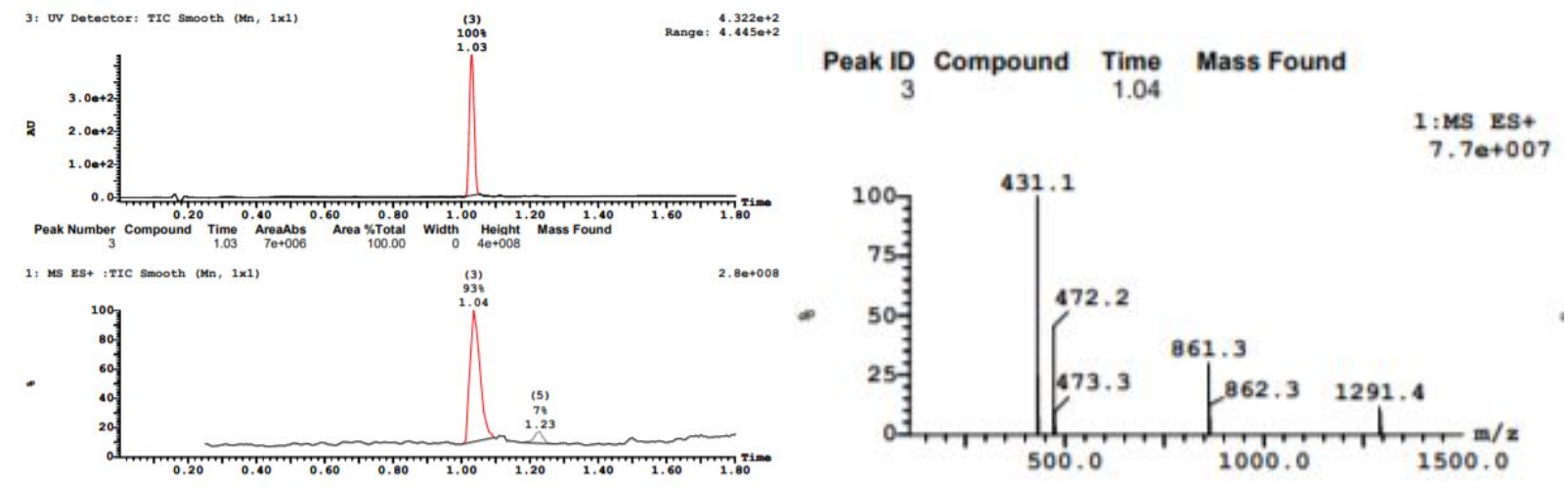

Compound 11
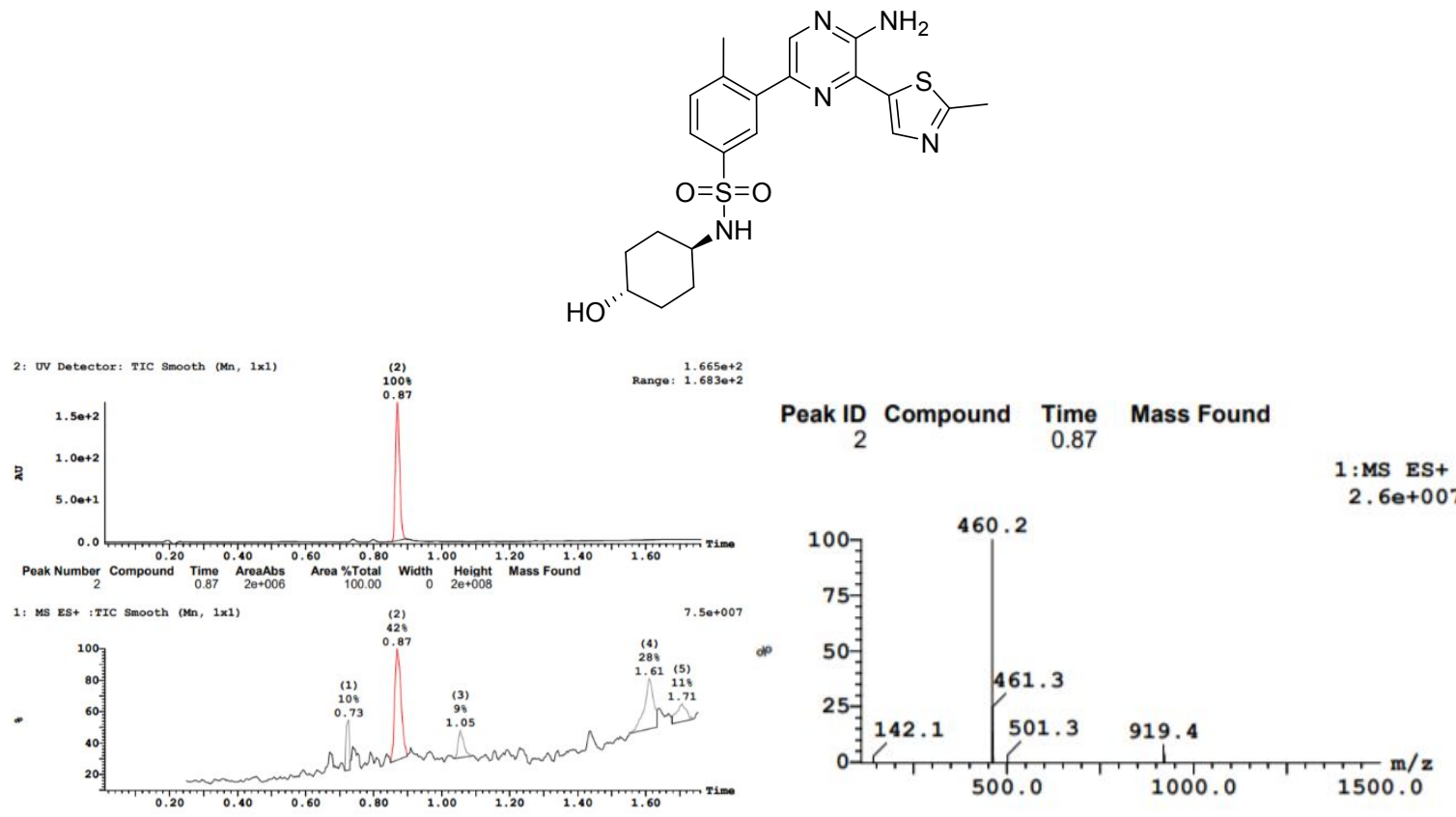

\section{Compound 12}

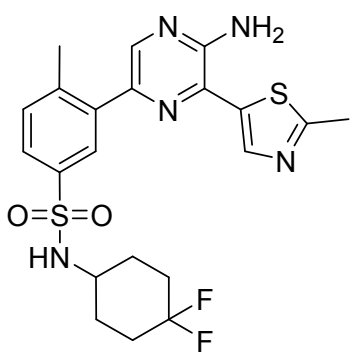




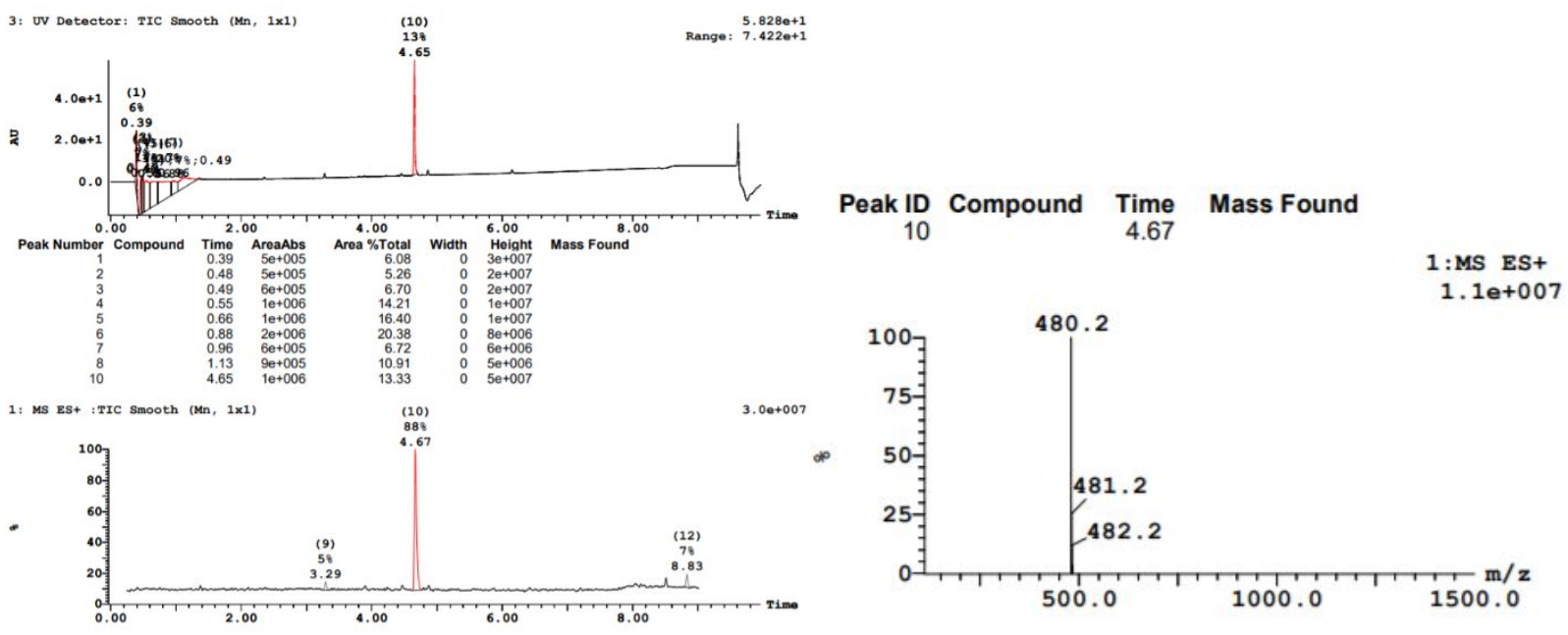

\section{Compound 13}
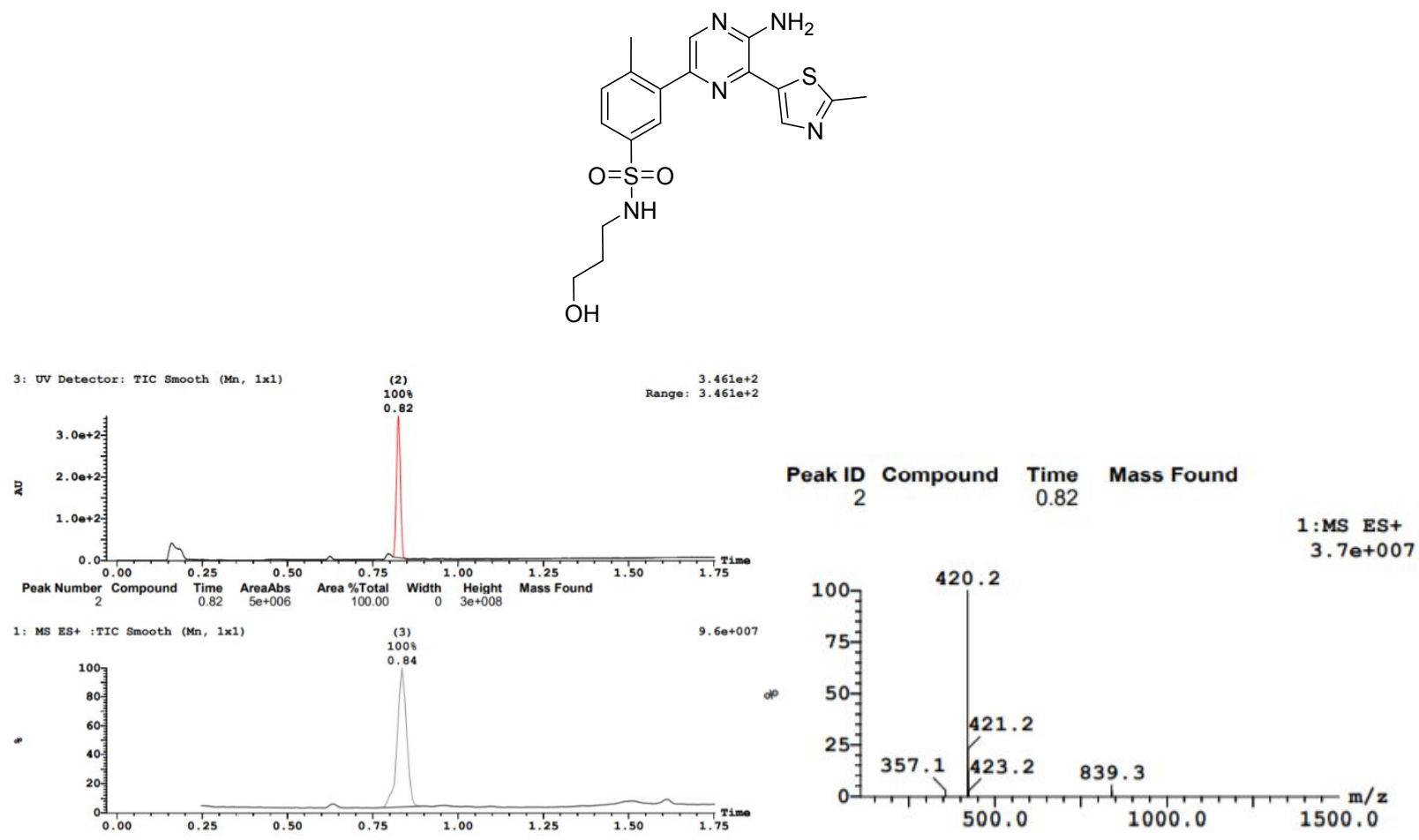

\section{Compound 14}



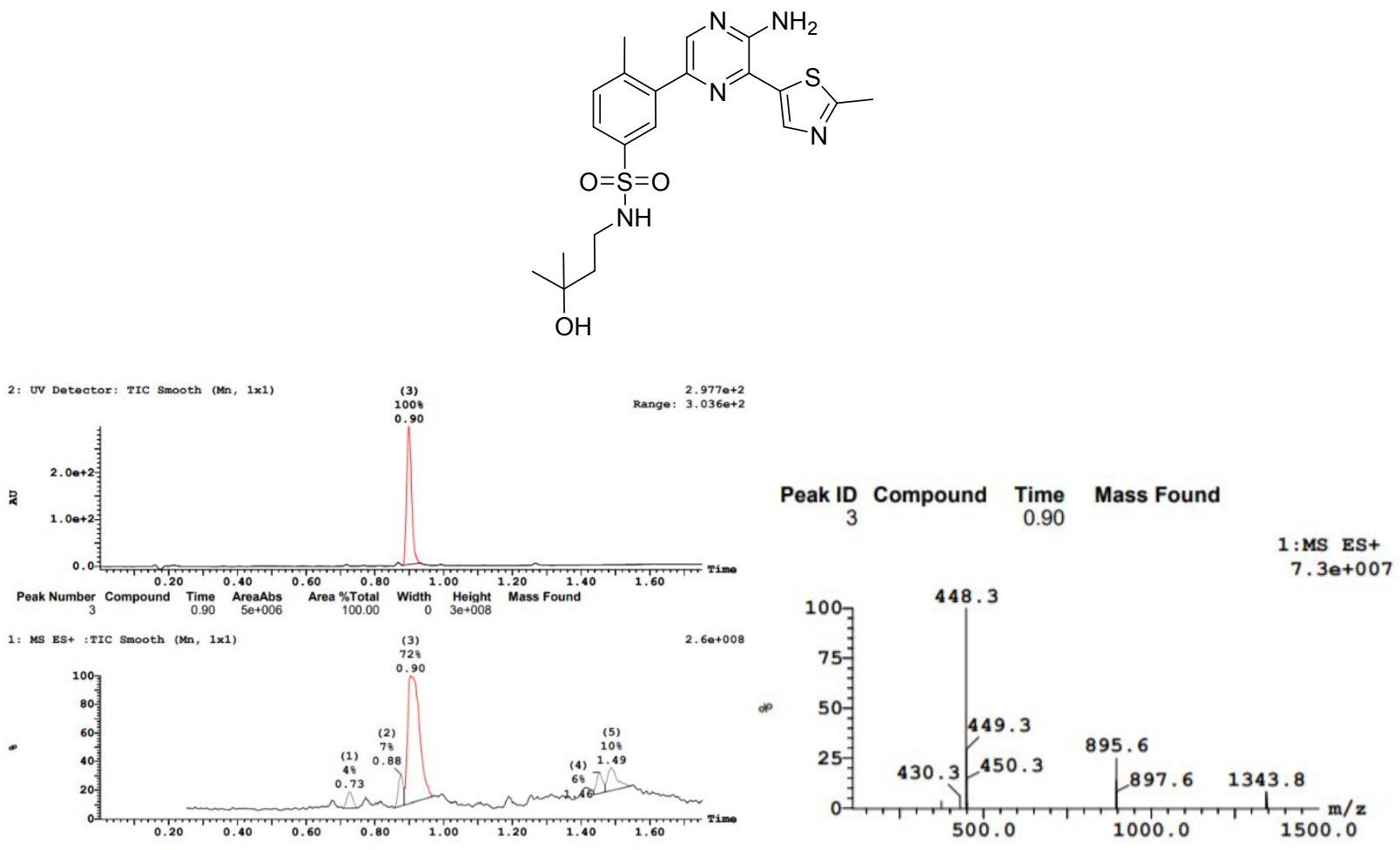

\section{Compound 15}
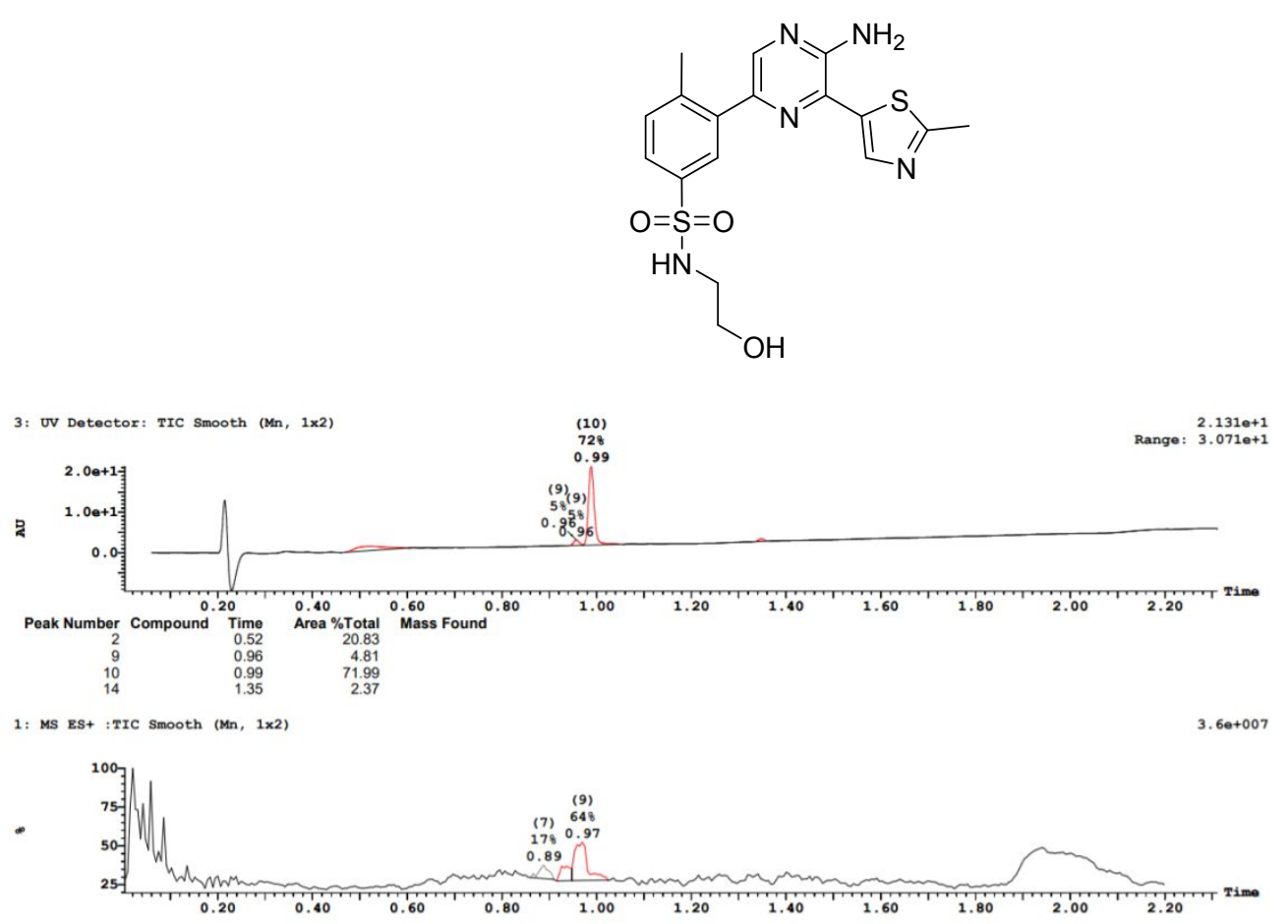


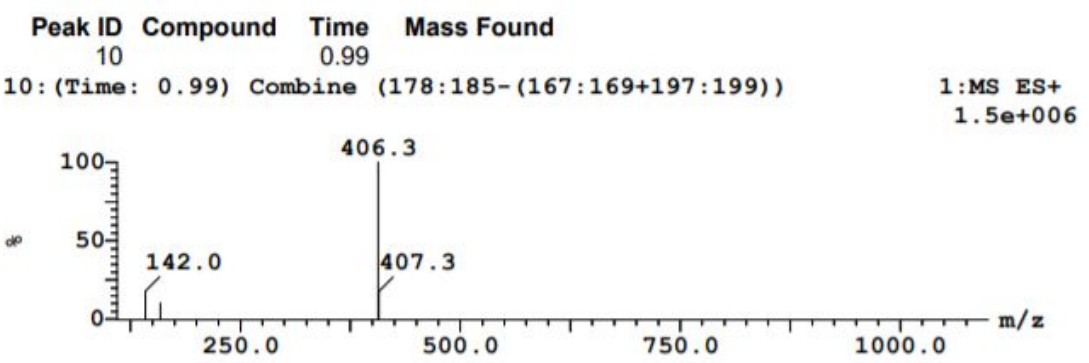

\section{Compound 16}
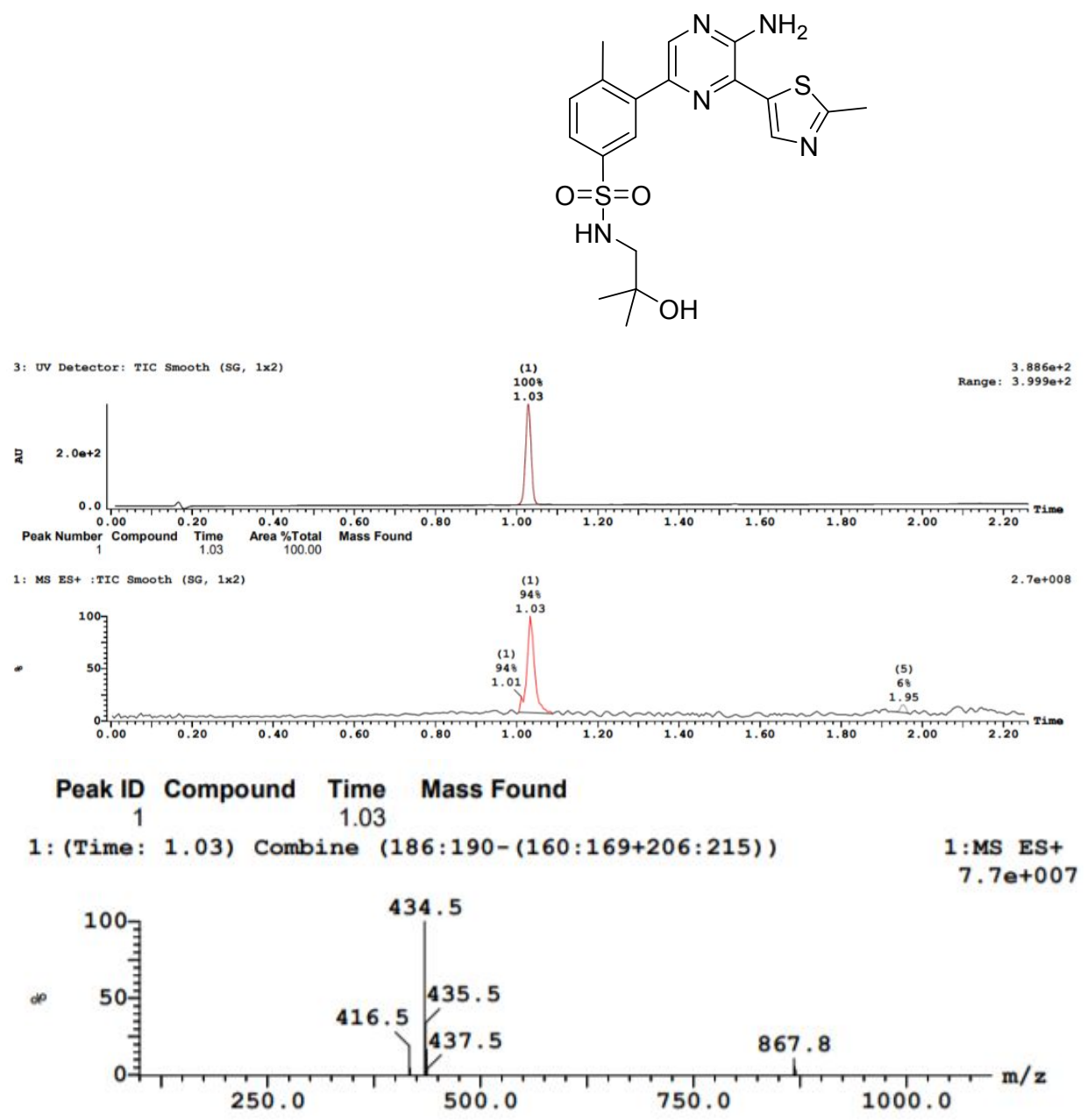

\section{Compound 17}




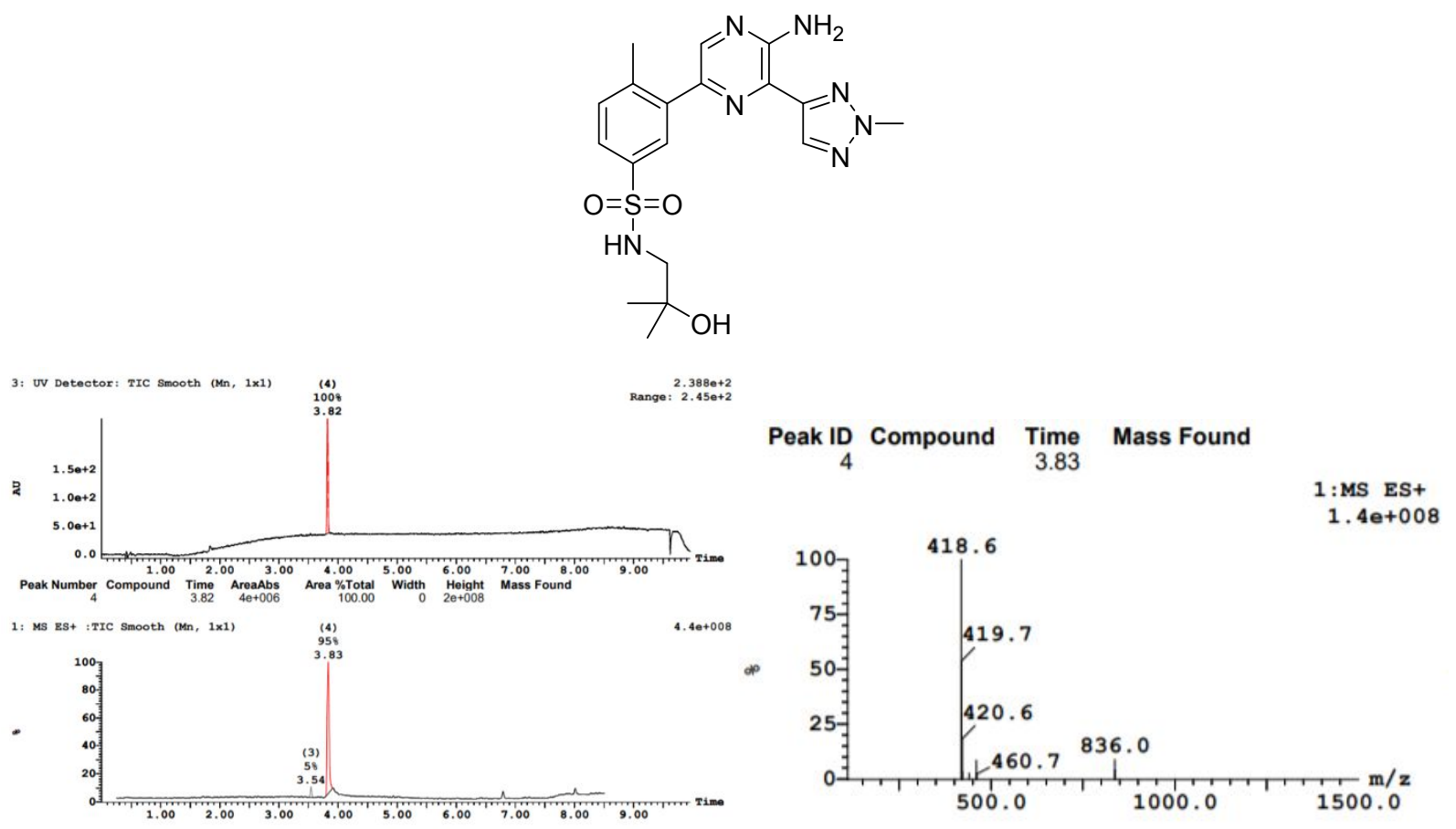

\section{Compound 18}
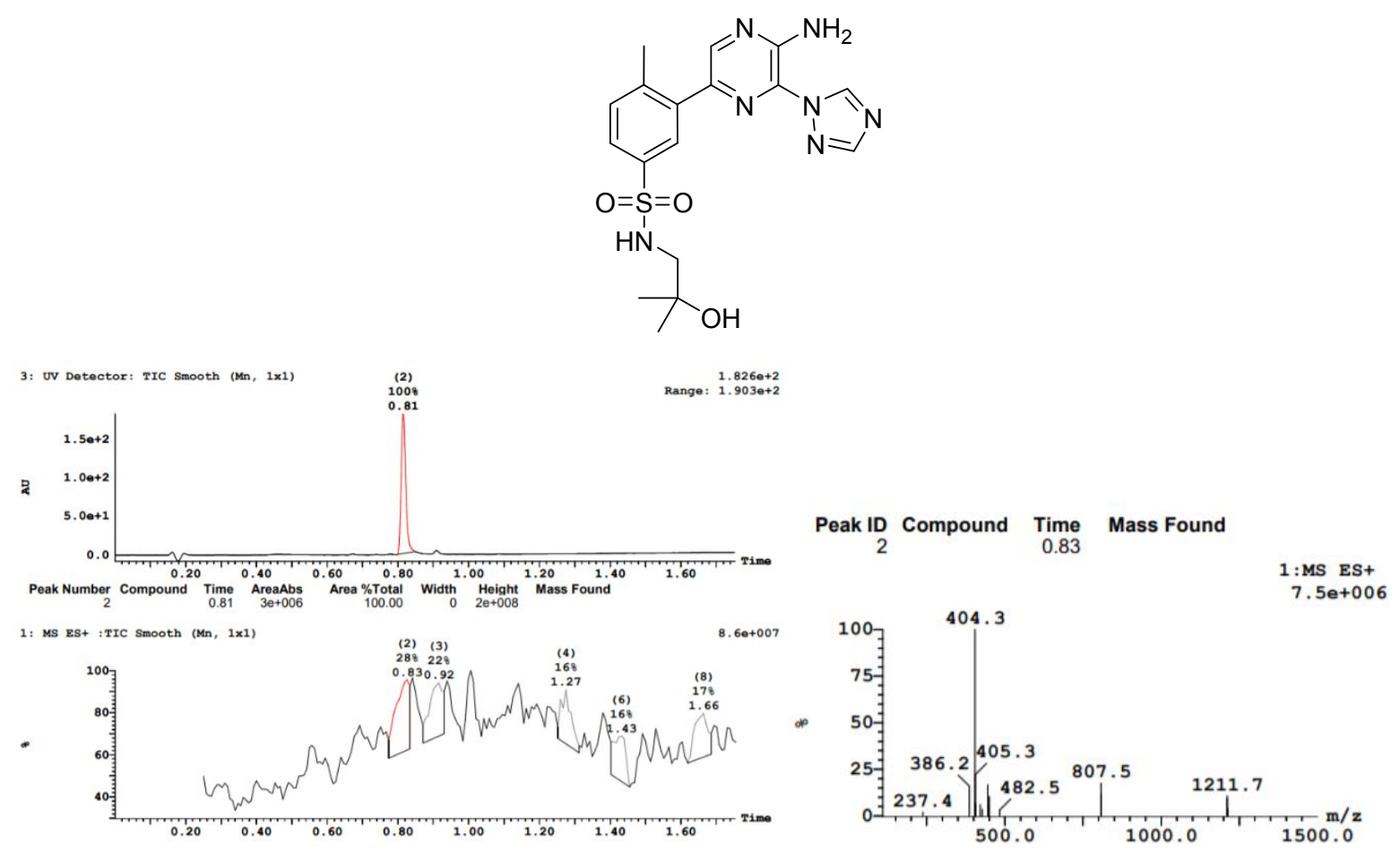

\section{Compound 19}




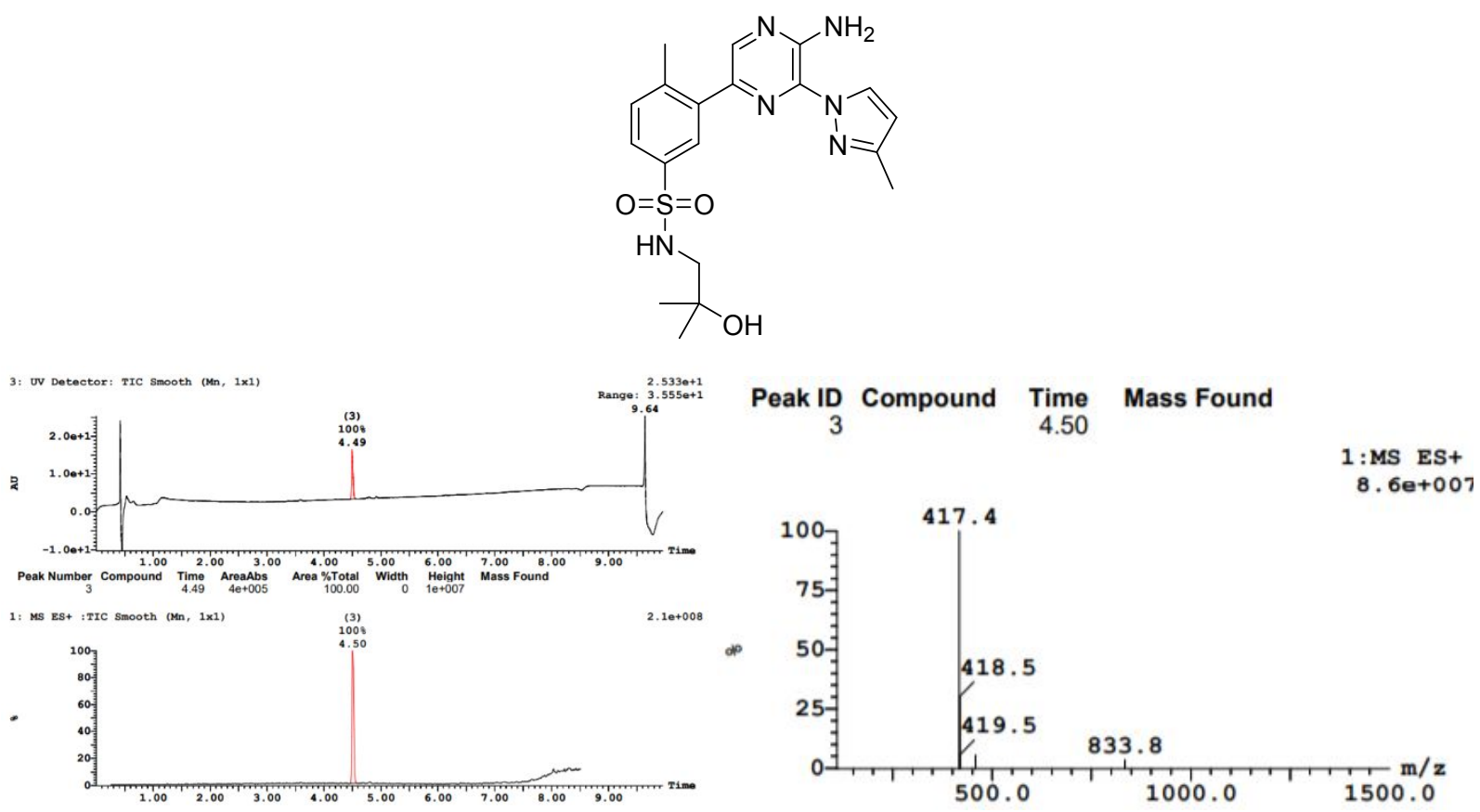

\section{Compound 20}
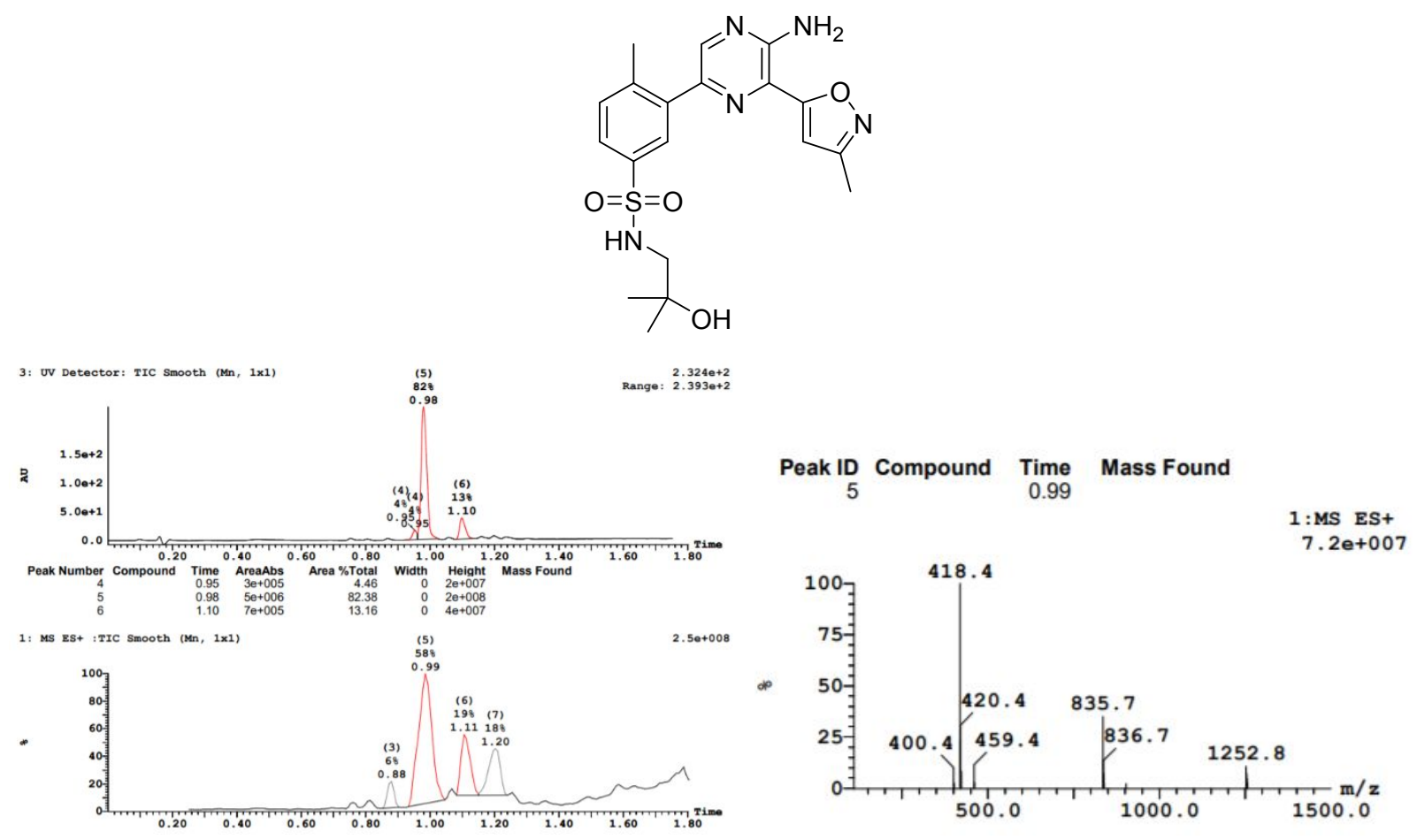

\section{Compound 21}




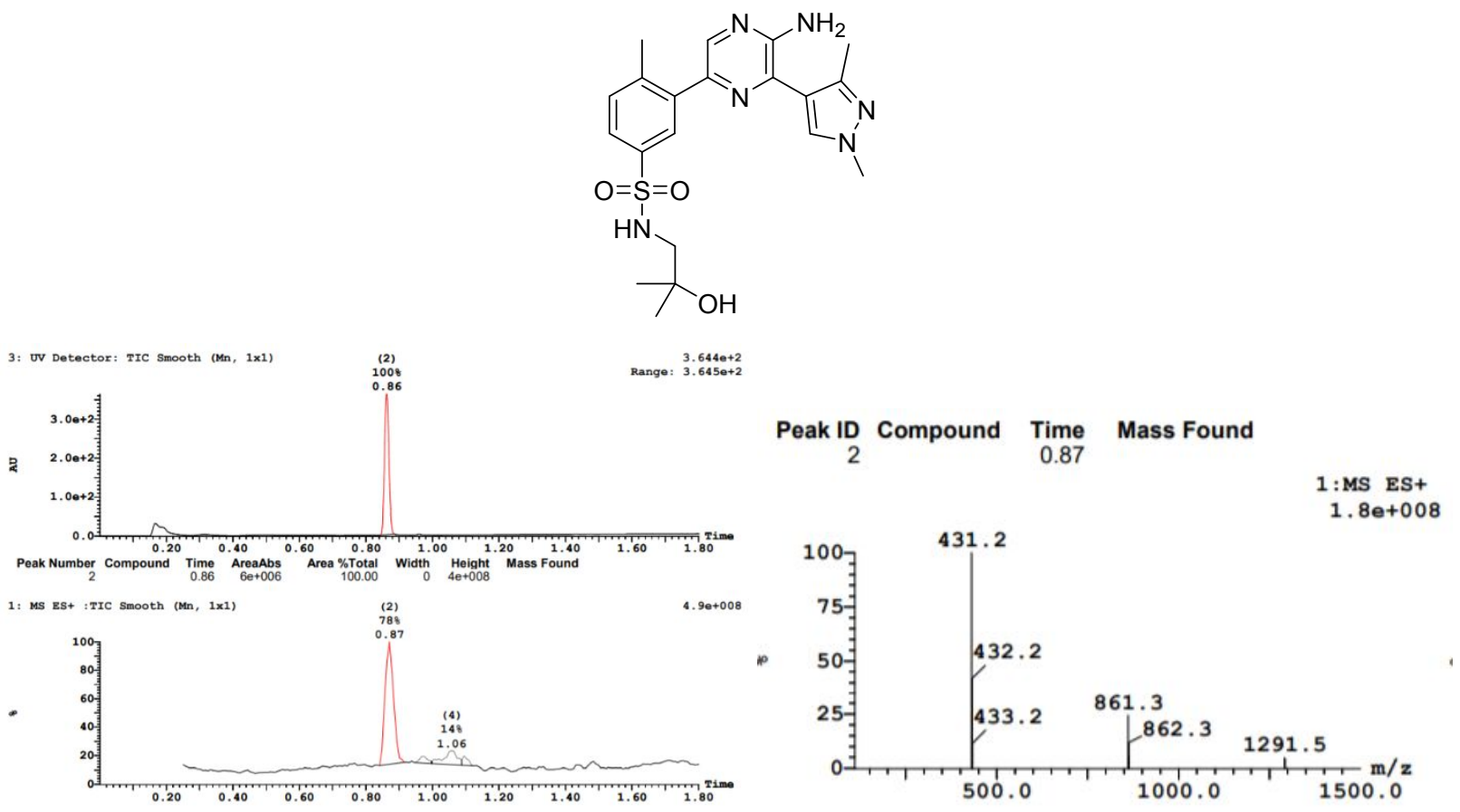

\section{Compound 22}
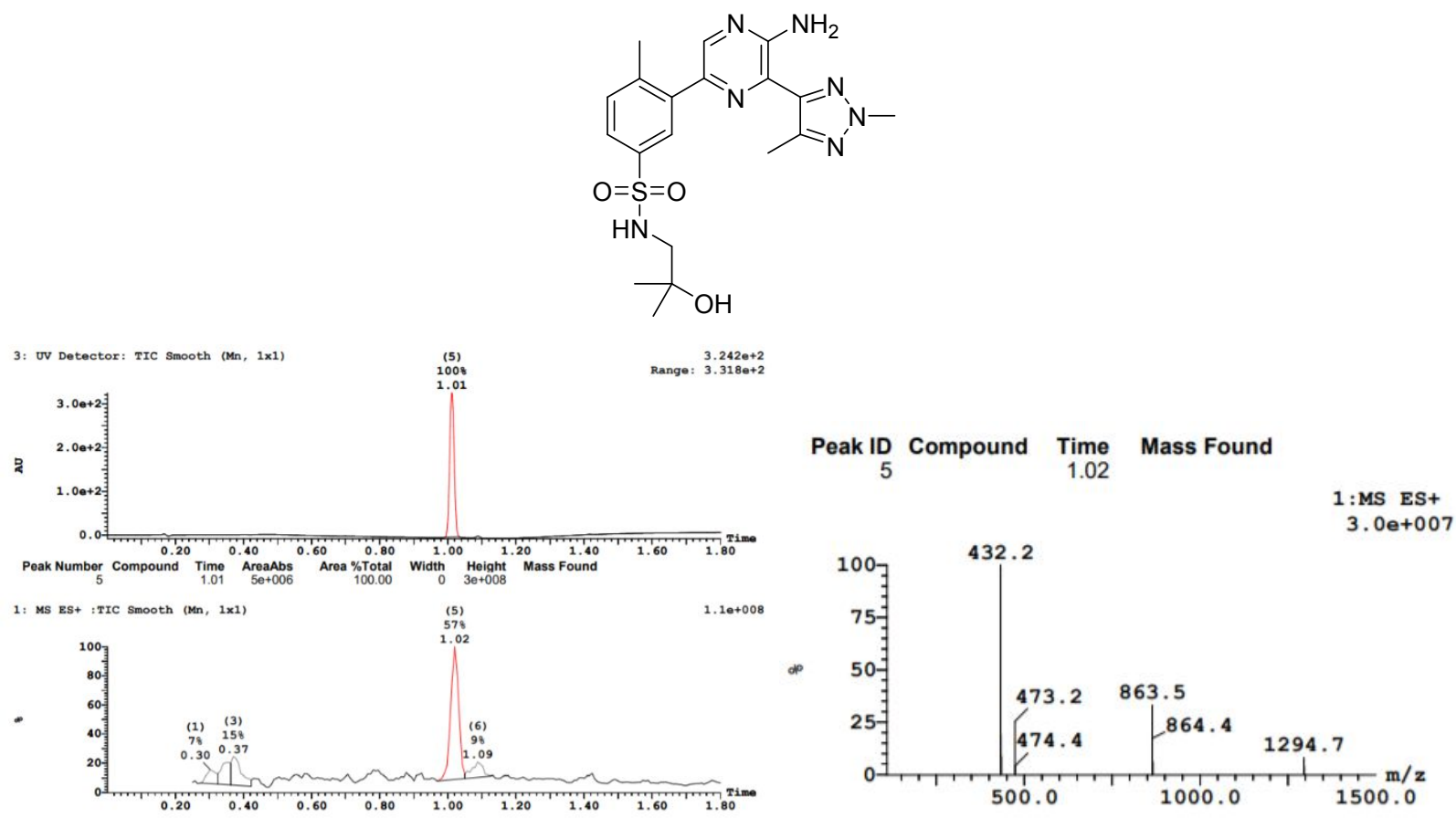

\section{Compound 23}



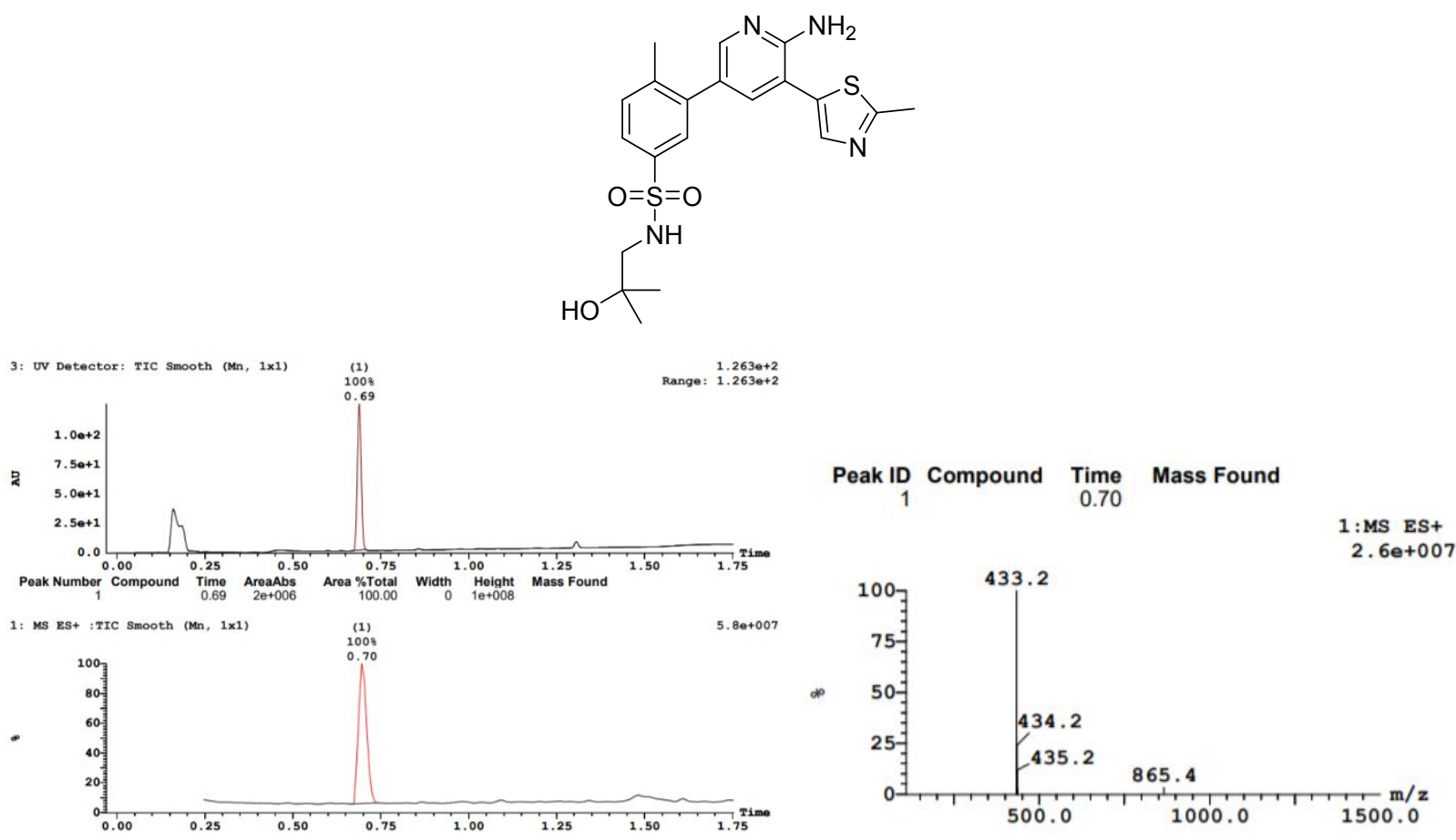

\section{Example 24}
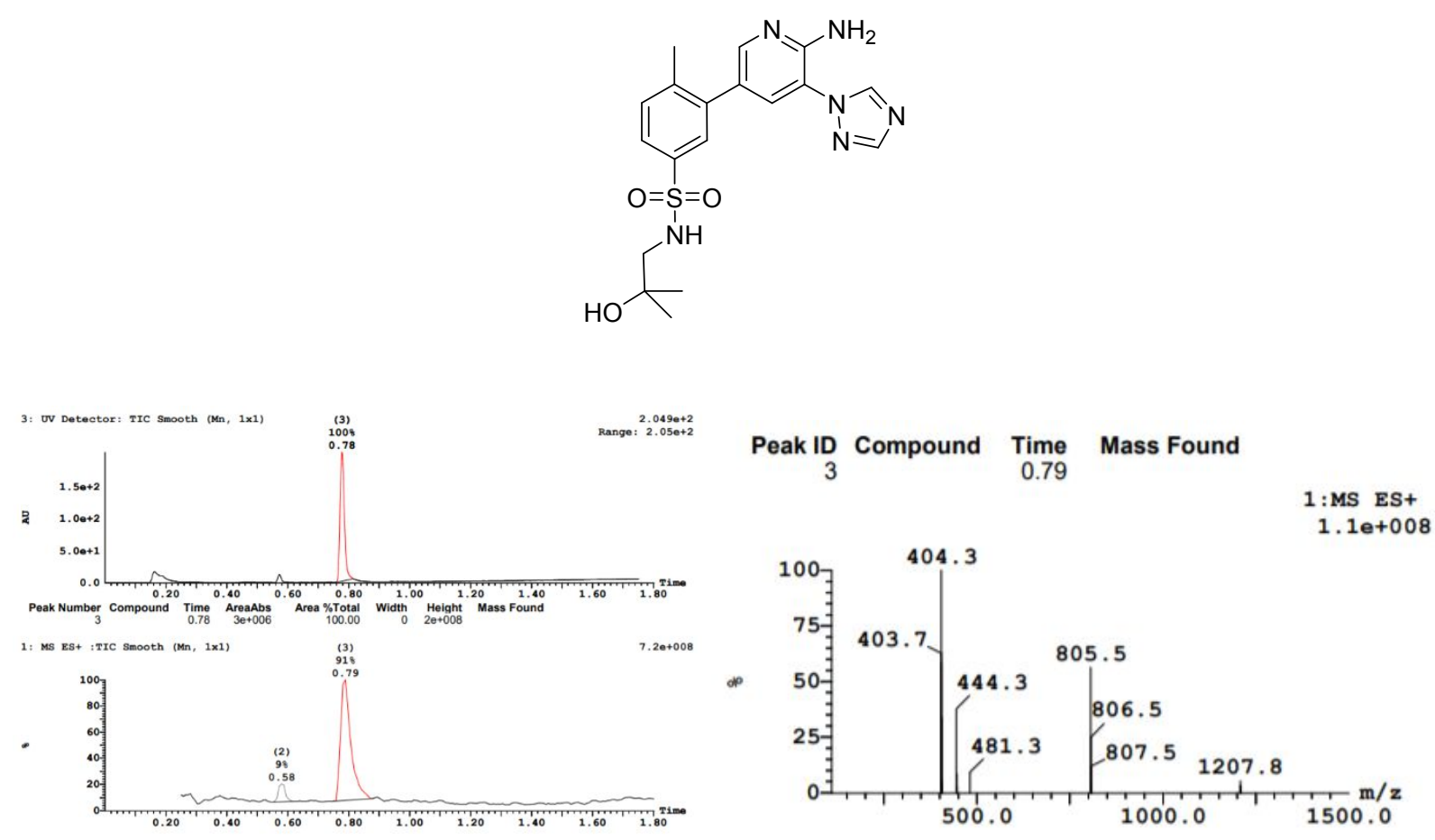

\section{Compound 25}



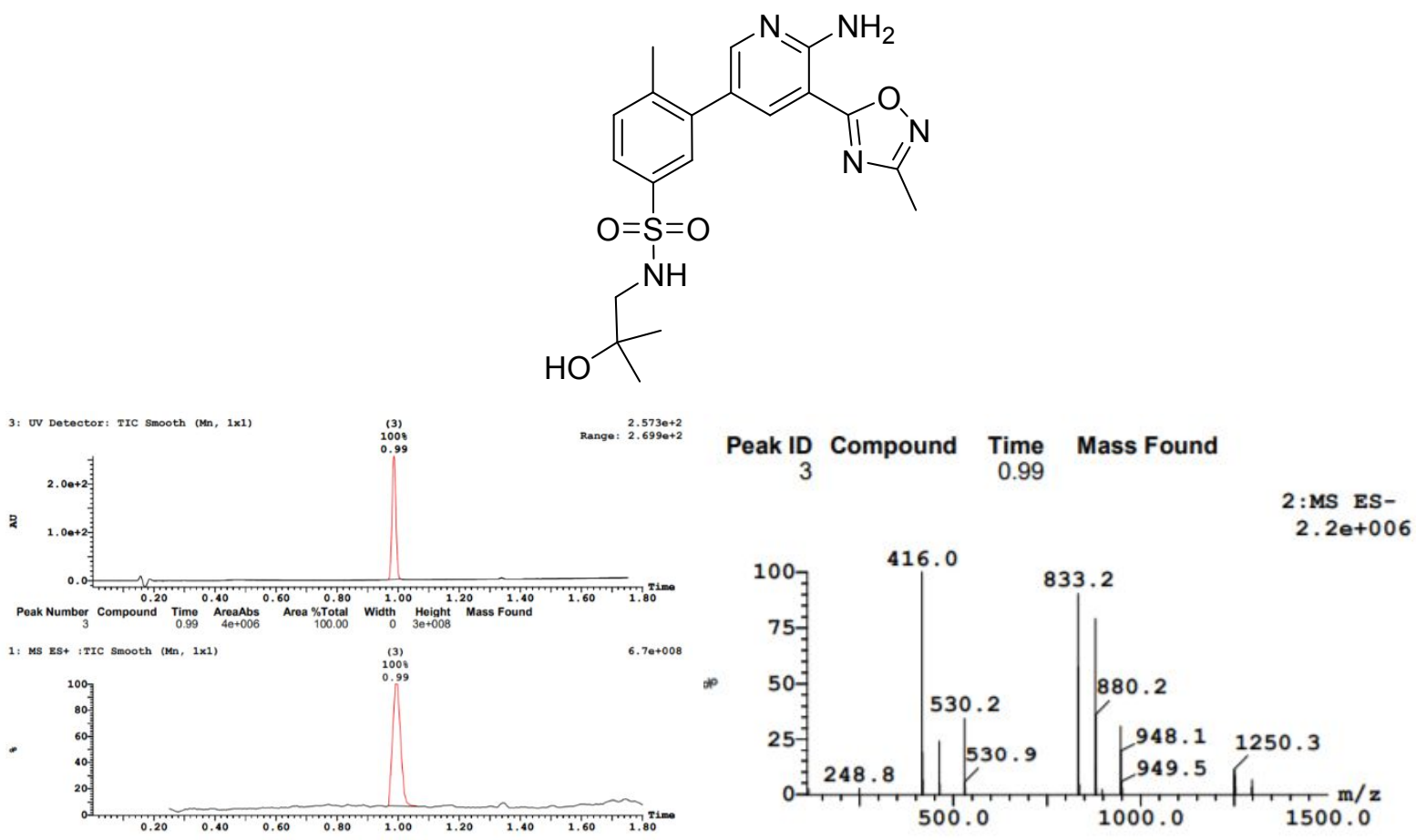

\section{Compound 26}

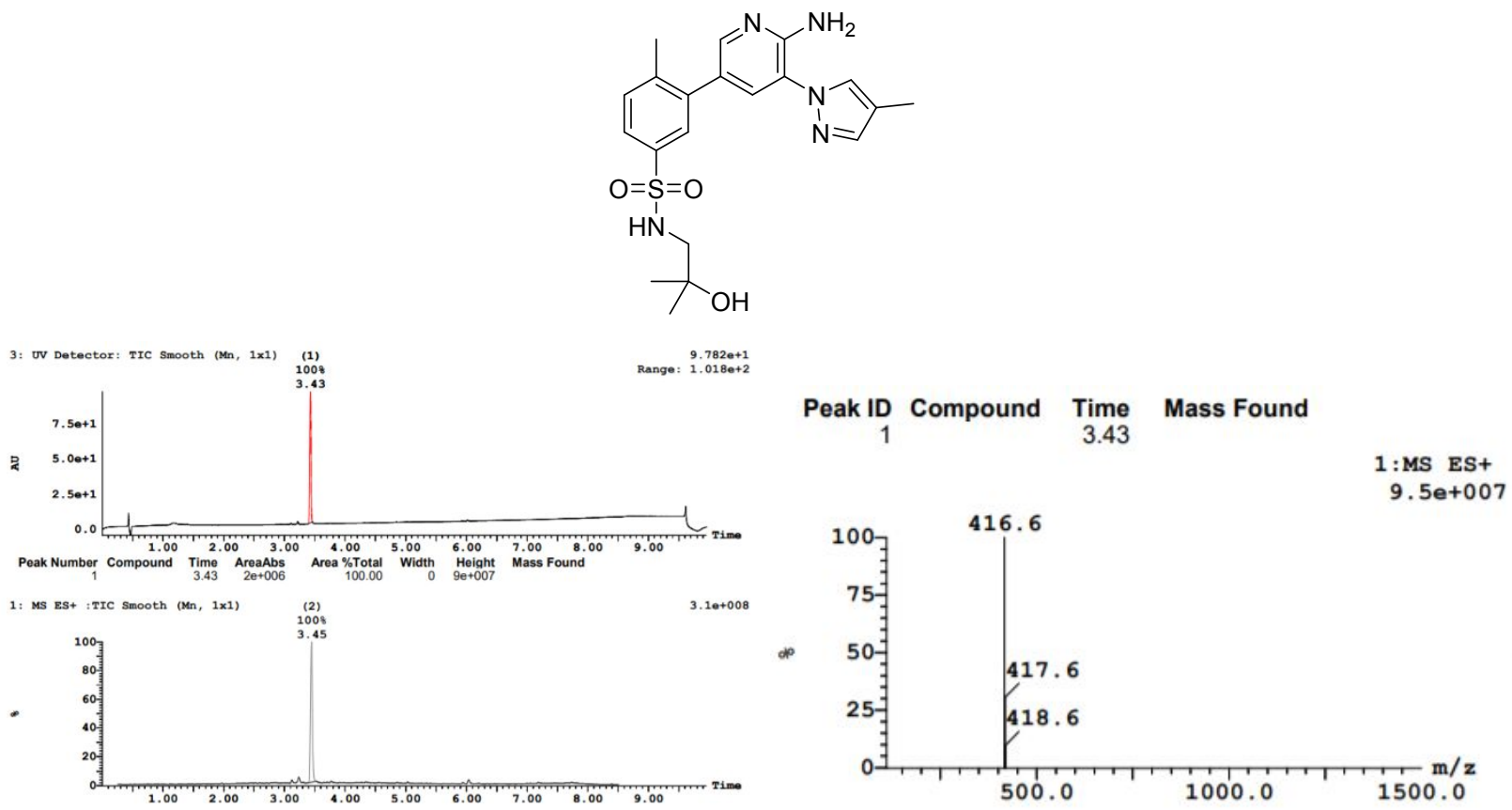

\section{Compound 27}



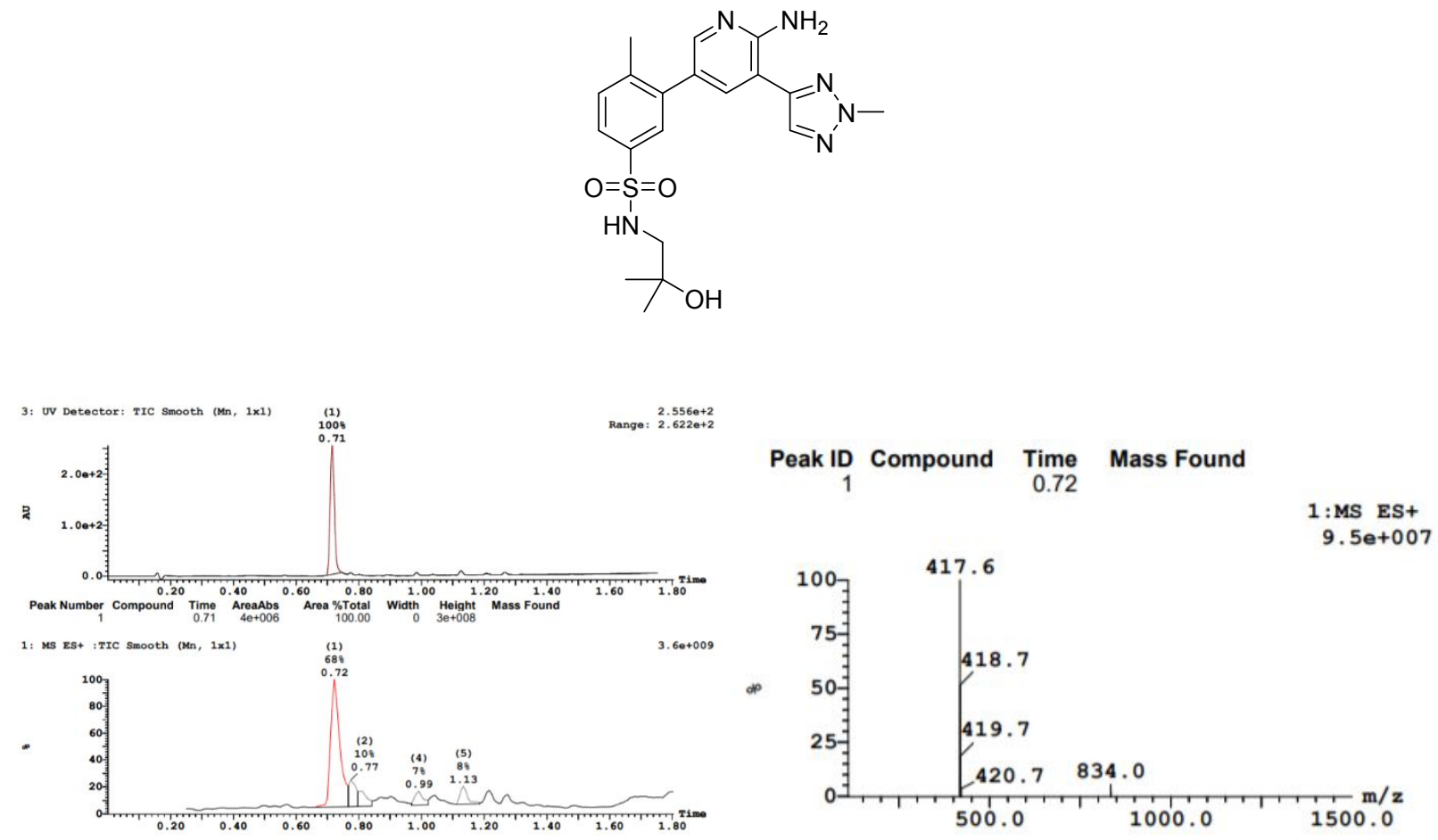

\section{Compound 28}
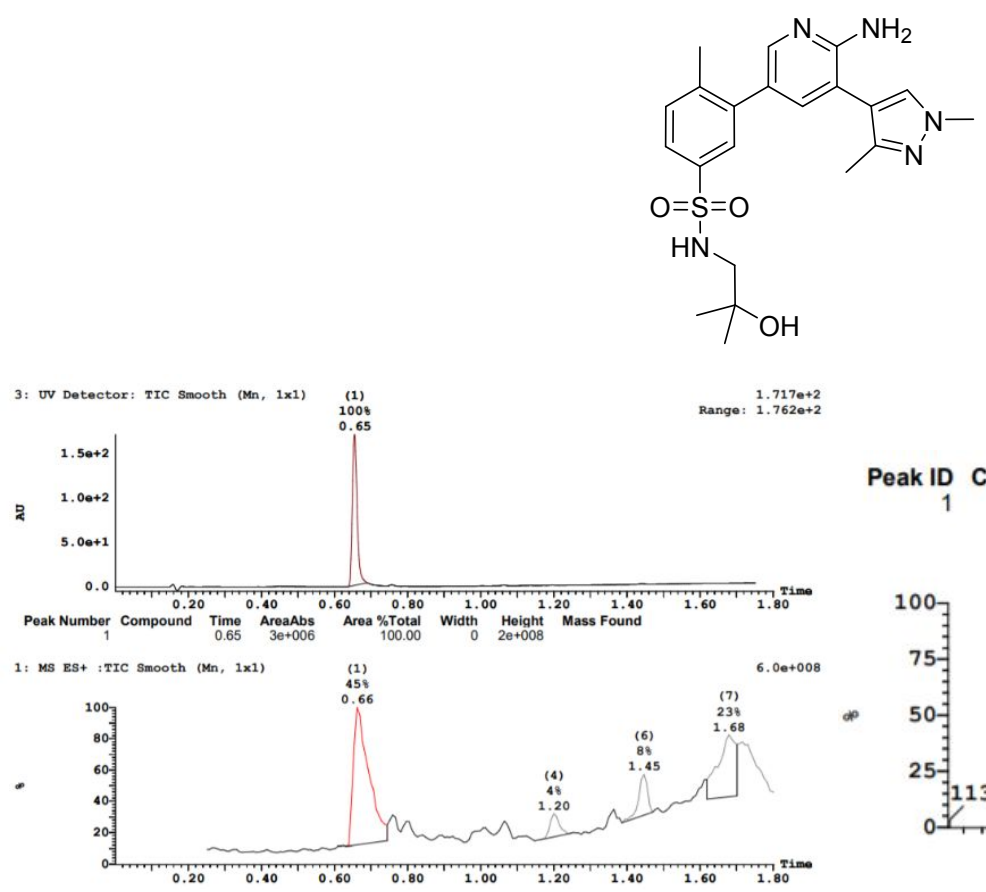

Peak ID Compound $\begin{array}{r}\underset{1}{\text { Time }} \\ 0.66\end{array} \quad$ Mass Found

2 :MS ES-

1. $2 e+007$

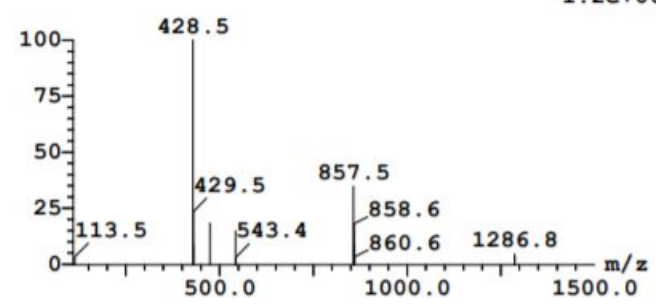

\section{Compound 29}



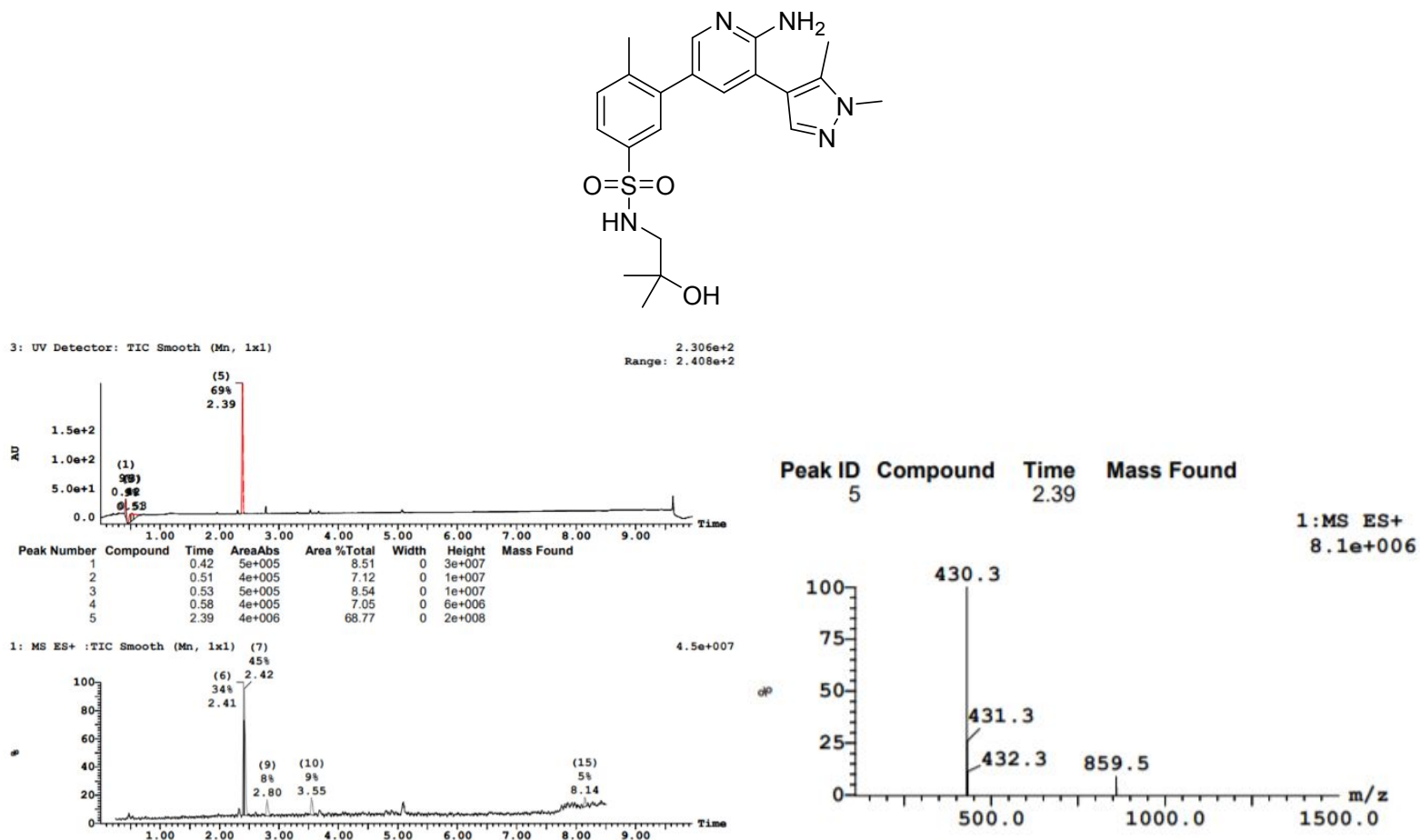

\section{Compound 30}

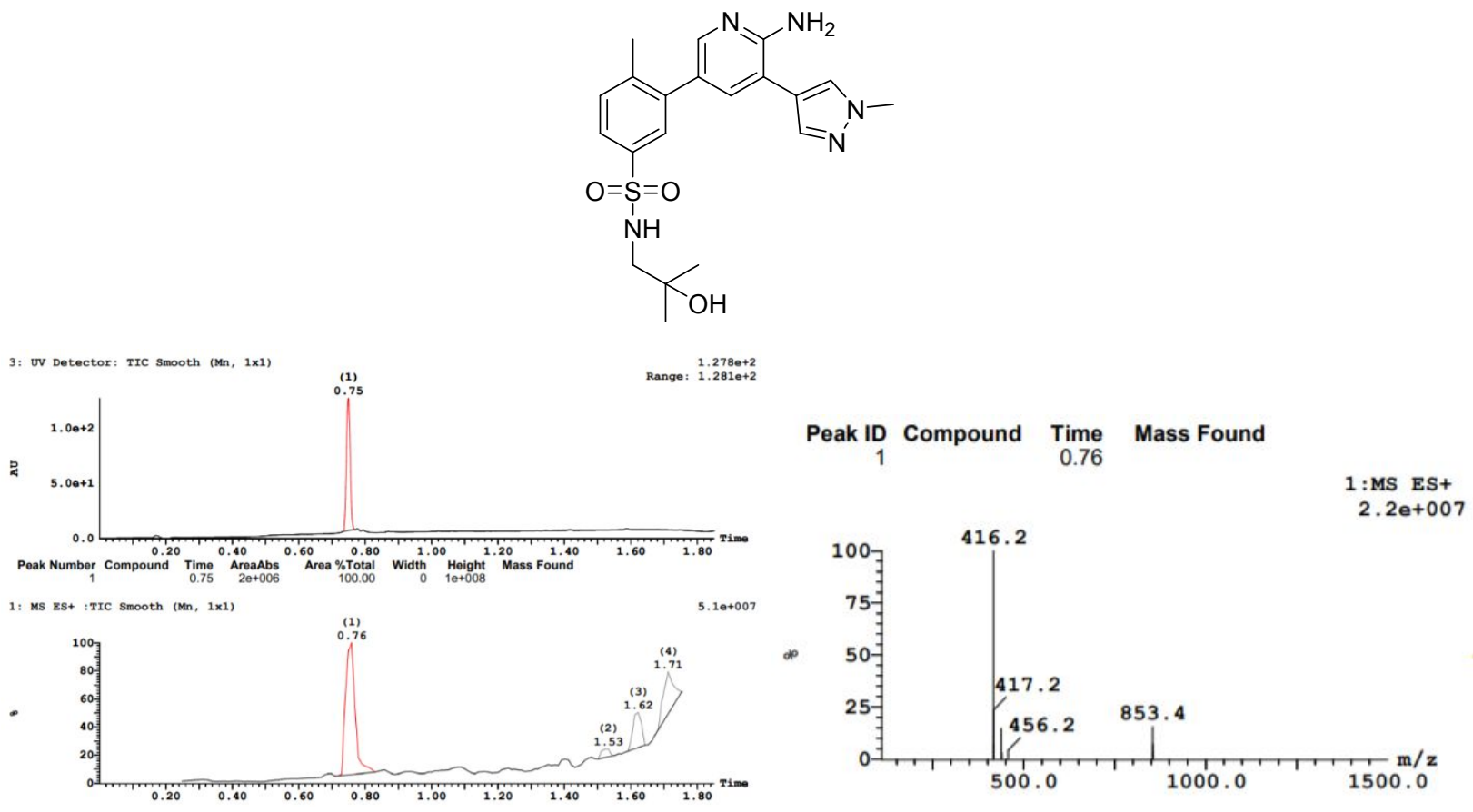




\section{Compound 31}

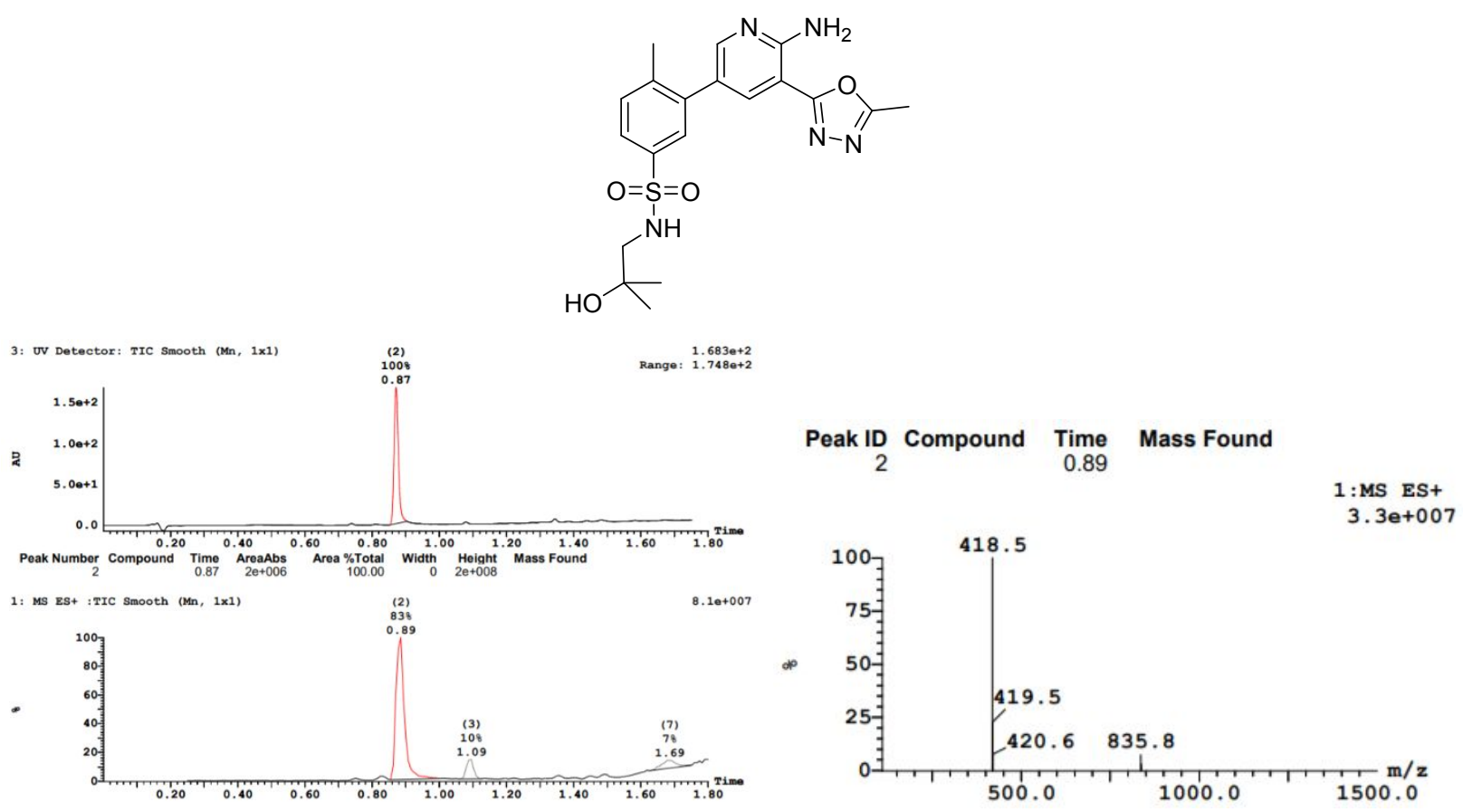

\section{Compound 32}
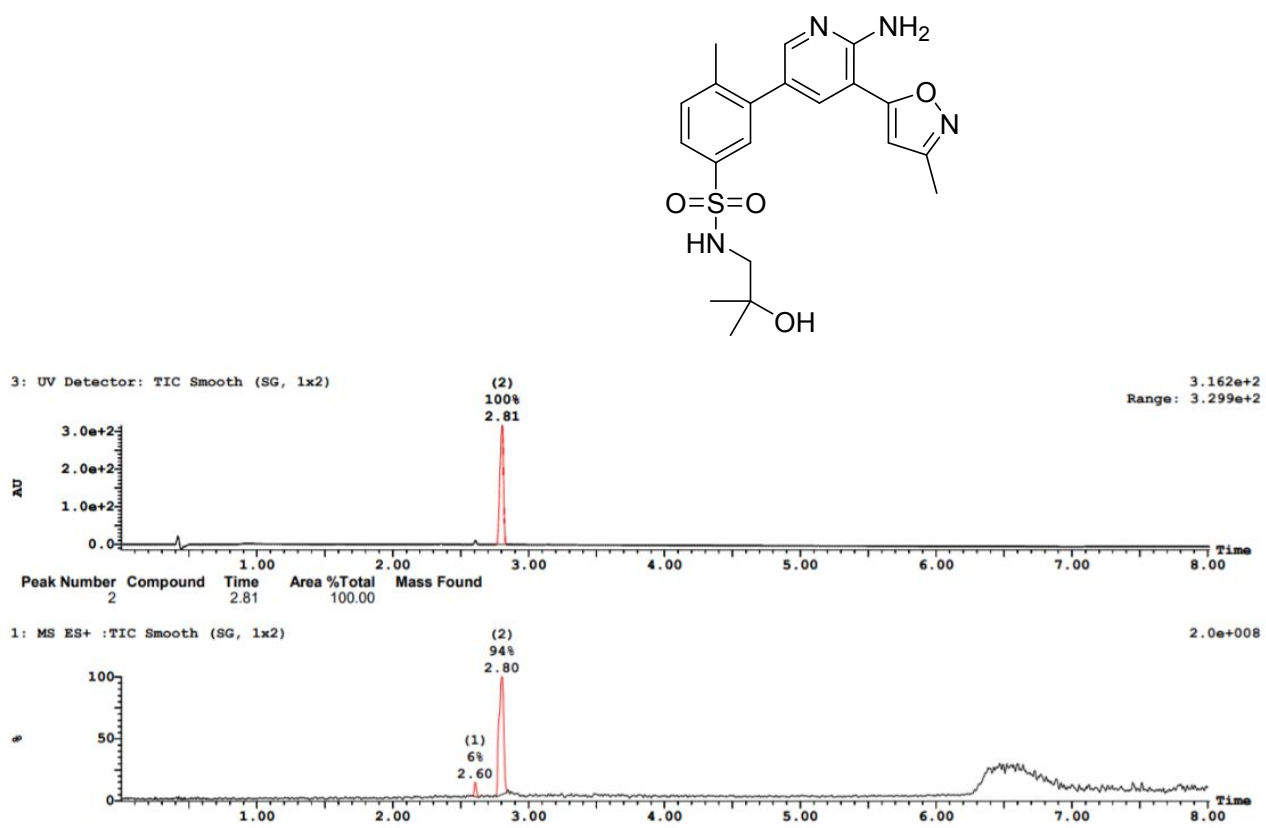


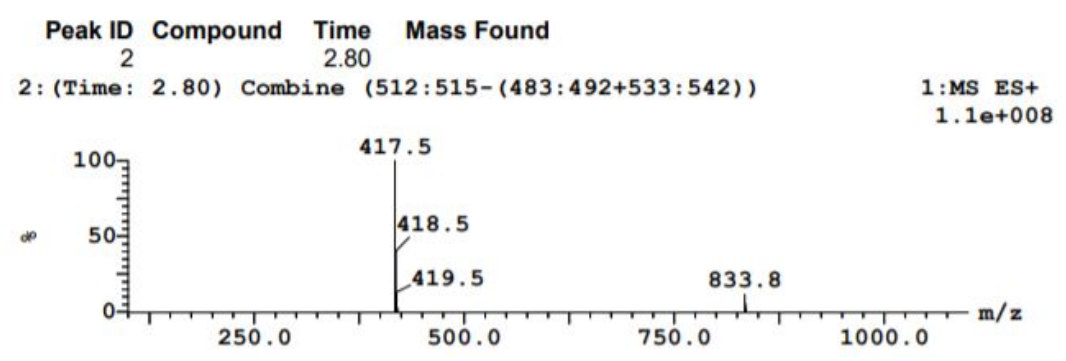

\section{Compound 33}
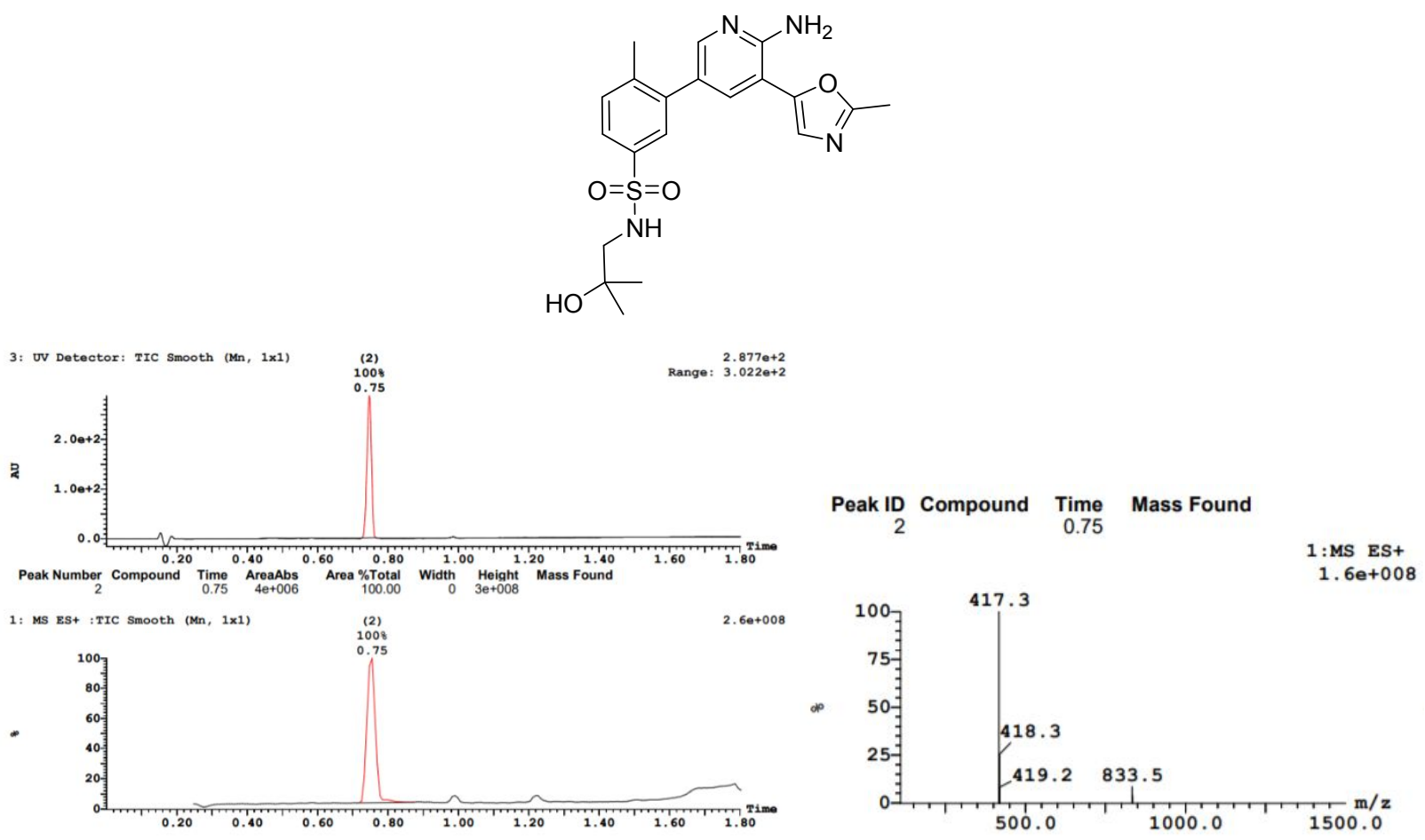

\section{Abbreviations:}

ADP: $\quad$ Adenosine diphosphate

ATP: $\quad$ Adenosine triphosphate

BSA: $\quad$ Bovine serum albumin

DMEM: Dulbecco's modified Eagle's medium

DMSO: $\quad$ Dimethylsulfoxide

DTT: Dithiothreitol

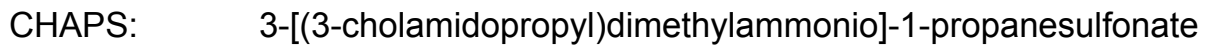

EDTA: $\quad$ Ethylenediaminetetraacetic acid 


\begin{tabular}{|c|c|}
\hline EGTA: & Ethylene glycol tetraacetic acid \\
\hline FACS: & Fluorescence-activated cell sorting \\
\hline FBS: & Fetal bovine serum \\
\hline HBSS: & Hank's Balanced Salt Solution \\
\hline HEPES: & 4-(2-Hydroxyethyl)piperazine-1-ethanesulfonic acid \\
\hline HTRF: & Homogeneous Time Resolved Fluorescence \\
\hline MIP1a: & Macrophage Inflammatory Protein form 1a (also known as CCL3) \\
\hline PBS: & phosphate-buffered saline \\
\hline RPMI: & Roswell Park Memorial Institute medium \\
\hline TR-FRET: & Time-Resolved Fluorescence Resonance Energy Transfer \\
\hline $\mathrm{AcOH}$ & acetic acid \\
\hline aq. & aqueous \\
\hline $\mathrm{br}$ & broad \\
\hline $\mathrm{BuOH}$ & butanol \\
\hline Celite $®$ & diatomaceous earth filter material \\
\hline conc. & concentrated \\
\hline$d$ & doublet \\
\hline dd & doublet of doublets \\
\hline DCM & dichloromethane \\
\hline DCC & N,N'-dicyclohexylcarbodiimide \\
\hline DCE & 1,2-dichloroethane \\
\hline DEAD & diethyl azodicarboxylate \\
\hline DIPEA & diisopropylethylamine \\
\hline DMA & dimethylacetamide \\
\hline DME & 1,2-dimethoxyethane \\
\hline DMF & $\mathrm{N}, \mathrm{N}$-dimethylformamide \\
\hline DMSO & dimethylsulfoxide \\
\hline $\mathrm{Et}_{2} \mathrm{O}$ & diethyl ether \\
\hline
\end{tabular}




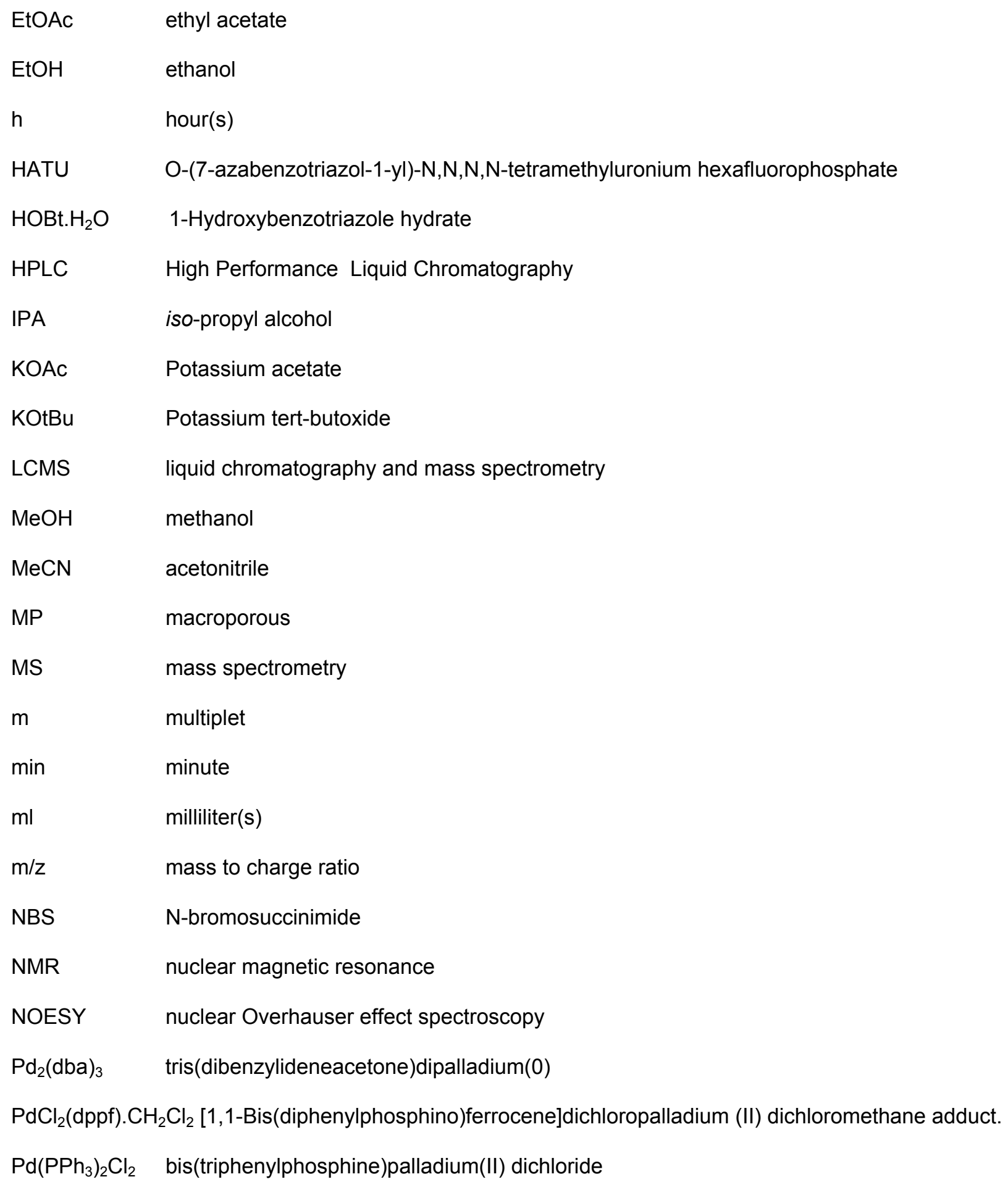




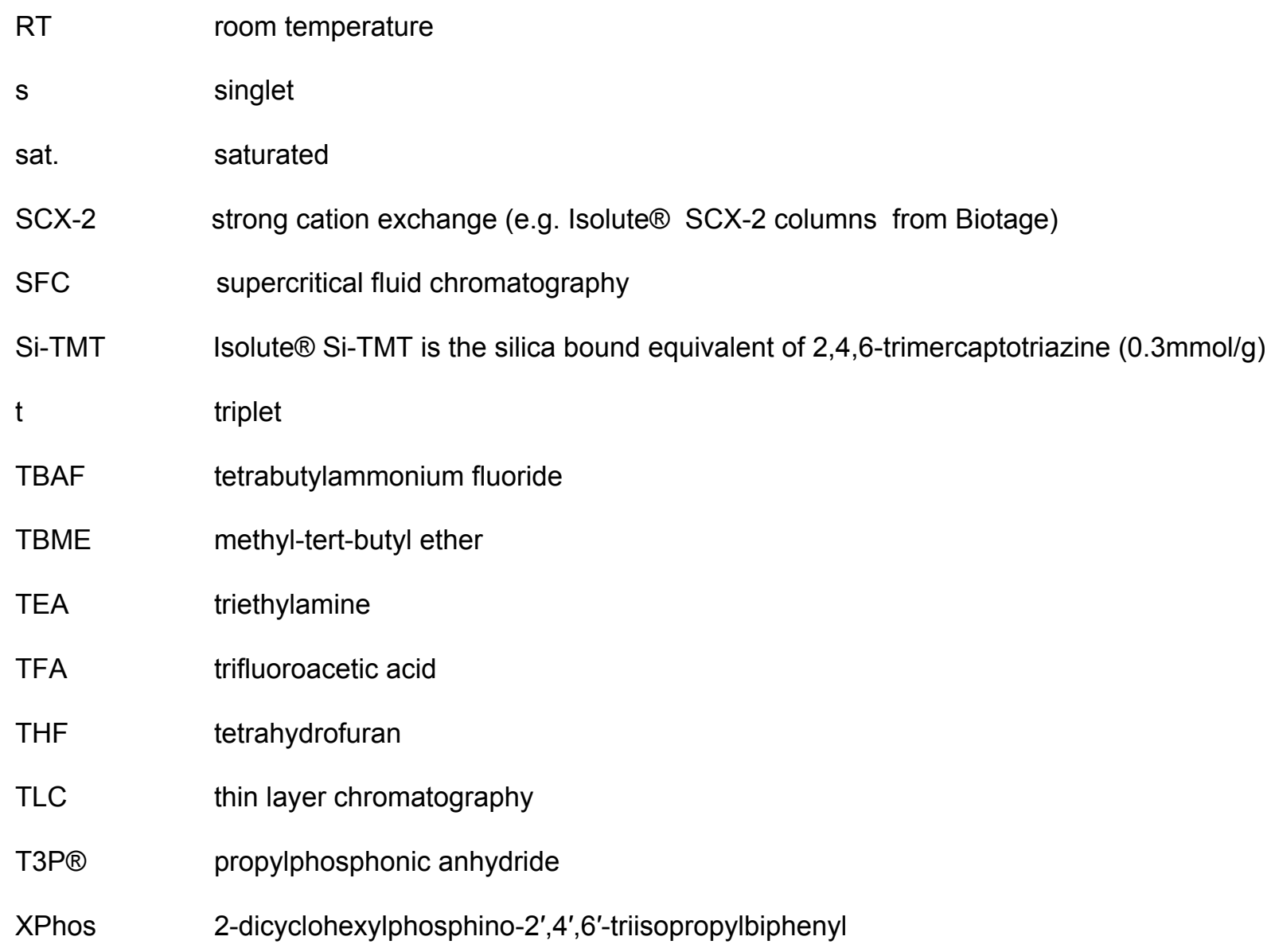

